Article

\title{
Energy-Efficient Fuzzy Management System for Internet of Things Connected Vehicular Ad Hoc Networks
}

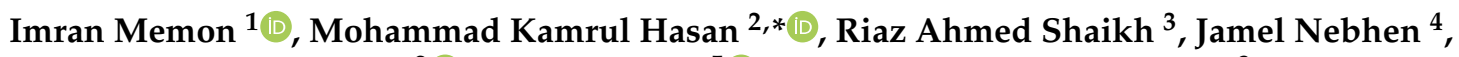 \\ Khairul Azmi Abu Bakar ${ }^{2}{ }^{(D}$, Eklas Hossain ${ }^{5}\left(\mathbb{D}\right.$ and Muhammad Hanif Tunio ${ }^{3}$ \\ 1 Department of Computer Science, Bahria University, Karachi 75260, Pakistan; \\ Iranmemon.bukc@bahria.edu.pk \\ 2 Center for Cyber Security, Faculty of Information Science and Technology, University Kebangsaan \\ Malaysia (UKM), Bangi 43600, Malaysia; khairul.azmi@ukm.edu.my \\ 3 Department of Computer Science, Shah Abdul Latif University, Sindh 66111, Pakistan; \\ riaz.shaikh@salu.edu.pk (R.A.S.); hanif.tunio@salu.edu.pk (M.H.T.) \\ 4 College of Computer Engineering and Sciences, Prince Sattam bin Abdulaziz University, \\ Alkharj 11942, Saudi Arabia; j.nebhen@psau.edu.sa \\ 5 Department of Electrical and Renewable Energy, Oregon Institute of Technology, \\ Klamath Falls, OR 97601, USA; eklas.hossain@oit.edu \\ * Correspondence: mkhasan@ukm.edu.my or hasankamrul@ieee.org
}

check for updates

Citation: Memon, I.; Hasan, M.K.; Shaikh, R.A.; Nebhen, J.; Bakar, K.A.A.; Hossain, E.; Tunio, M.H. Energy-Efficient Fuzzy Management System for Internet of Things Connected Vehicular Ad Hoc Networks. Electronics 2021, 10, 1068. https://doi.org/10.3390/electronics 10091068

Academic Editor: Fernando A. Silva

Received: 5 March 2021

Accepted: 8 April 2021

Published: 30 April 2021

Publisher's Note: MDPI stays neutral with regard to jurisdictional claims in published maps and institutional affiliations.

Copyright: (c) 2021 by the authors. Licensee MDPI, Basel, Switzerland. This article is an open access article distributed under the terms and conditions of the Creative Commons Attribution (CC BY) license (https:// creativecommons.org/licenses/by/ $4.0 /)$.

\begin{abstract}
Many algorithms use clustering to improve vehicular ad hoc network performance. The expected points of many of these approaches support multiple rounds of data to the roadside unit and constantly include clustering in every round of single-hop data transmission towards the road side unit; however, the clustering in every round maximizes the number of control messages and there could be the possibility of collision and decreases in network energy. Multi-hop transmission prolongs the cluster head node's lifetime and boosts the network's efficiency. Accordingly, this article proposes a new fuzzy-clustering-based routing algorithm to benefit from multi-hop transmission clustering simultaneously. This research has analyzed the limitation of clustering in each round, different algorithms were used to perform the clustering, and multi-hop routing was used to transfer the data of every cluster to the road side unit. The fuzzy logic was used to choose the head node of each cluster. Three parameters, (1) distance of each node, (2) remaining energy, and (3) number of neighbors of every node, were considered as fuzzy criteria. The results of this research were compared to various other algorithms in relation to parameters like dead node in every round, first node expire, half node expire, last node expire, and the network lifetime. The simulation results show that the proposed approach outperforms other methods. On the other hand, the vehicular ad hoc network (VANET) environment is vulnerable at the time of data transmission. The NS-2 software tool was used to simulate and evaluate the proposed fuzzy logic opportunistic routing's performance results concerning end-to-end delay, packet delivery, and network throughput. We compare to the existing protocols, such as fuzzy Internet of Things (IoT), two fuzzy, and FuzzyBased Driver Monitoring System (FDMS). The performance comparison also emphasizes an effective utilization of the resources. Simulations on the highway environment show that the suggested protocol has an improved Quality of Service (QoS) efficiency compared to the above published methods in the literature.
\end{abstract}

Keywords: fuzzy logic; IoT; intelligent system; energy efficiency

\section{Introduction}

The collection of network's physical items (nodes) embedded with software, actuators, sensors, and other various connectivity modules that allow them to send and receive data is considered the Internet of Things (IoT). A number of transmission medium technologies can be used by IoT, such as Wireless Fidelity (Wi-Fi), Bluetooth, and ZigBee, in which 
nodes can share data in both infrastructures in an ad hoc way. Because of the huge number of nodes, the Internet of Things (IoT) accommodates huge amounts of data; moreover, these nodes are usually battery-powered, so they have a tendency toward energy depletion. However, traffic jamming is one of the most common and serious issues faced by small to big cities globally and has challenged the public's lives in a challenging environment. The smart cities in the world would like to plan a strategy to decrease their transportation problem because of the increasing population, which affects overfilled roads [1,2]. Smart cities implement emerging computing technologies to make smart infrastructure objects, facilities, and other city services, which may include education, public safety, transportation, administration, healthcare, real estate, and more intelligent interconnected utilities [3].

The vehicular ad hoc networks (VANETs) can help to overcome this problem by increasing road safety and improving vehicles' mobility. The Internet of Things (IoT) is a fast-growing field in this modern digital era, with millions of functioning physical devices (nodes) interconnected to each other deprived of human interactivity [4]. The Internet of Things can flawlessly, constantly, and pervasively connect and control the real world's different objects through nodes (physical objects) with different types of intelligent wireless sensors. This multiple set of nodes present among the neighbors is defined as sending set [4]. Therefore, choosing an appropriate criterion to select the rebroadcasting node in opportunistic routing can improve the performance of inter-vehicle network characteristics. In addition, the car following model is limited to roads and highways. Hence, drivers must know the vehicle position and direction to make better decisions and avoid link disconnection. To obtain this information, the beacon messages will be used periodically between neighbors. These updates are very costly in many ways. Each update leads to increased bandwidth usage, packet advancement delay, and increased collision risk in the media access layer [5]. Packet collision will cause packet loss, affecting routing efficiency, and, consequently, a crowded condition occurs when the channel is used by vehicles. As a result, collisions will occur by increasing car densities, leading to increased congestion within the network. This crowded condition in the network causes an increase in pocket loss and delay, consequently decreasing the system functionality [6,7]. In this work, beacon messages were not used in the opportunistic routing protocol to solve this problem. They were introduced as a fault-tolerant protocol for vehicular networks that use the wireless channel broadcast feature and improve the network performance during data forwarding.

Additionally, the number of duplicated packets, packet advancement toward the destination, and density are used as the prioritization criteria for rebroadcasting nodes. In this way, the packets are transferred with the least consumed resources and provide appropriate performance considering opportunistic routing schemes. In our proposed method, it is unnecessary to send beacon packets to keep informed of the status of neighbors and the density of the network. Therefore, it is necessary to calculate these parameters; this leads to reduce the congestions and packet loss. Given the above-mentioned items, a fuzzy protocol is presented in this paper for decision-making on rebroadcasting the packets and their routings to the destination. This fuzzy protocol uses three input parameters with the objective of proper decision-making for rebroadcasting. Given the importance of the packet's advancement, the variation and local density of the vehicles, and controlling duplicate packets in the network, these three variables are chosen as the inputs to the fuzzy system for proper decision-making. The routing tries to choose the rebroadcasting nodes with the maximum advancement toward the destination.

Moreover, the local density of a parameter is dynamic in the network. Routing should make proper decisions considering the density. Finally, the number of duplications of the packets cause congestions and collisions in the network for which the routing should have required to control. Consequently, routing and packet rebroadcasting use fuzzy decision-making with these three parameters. For improving the limitations found in the research literature and for choosing the right routes for retransmission, we proposed the fuzzy logic to merge the following three concepts: (i) packet improvement to minimize delay between links; (ii) local control to manage rapid communicational changes, which 
may minimize retransmission and maximize throughput; and (iii) choosing nodes with the least number of received duplicate packets. With the implementation of fuzzy logic on the rebroadcasting physical device (node), the nearest best node is selected from the set of relays, leading to generating routes with maximum throughput and lower delay for end-to-end node with the effective rate of data delivery.

In multi-hop wireless sensor network unequal clustering, the size of clusters increases as the get farther from the road side unit. Therefore, when the nodes are densely aggregated around the roadside unit, the cluster head energy decreases rapidly. In addition to its packets, the cluster head node must guide other clusters' packets. Using the fuzzy system while considering measures like the grade of each device and its space (distance) to the road side unit leads to decreasing transmission delay, increasing network lifetime and decreasing energy consumption during cluster head selection and cluster formation $[7,8]$. Employing fuzzy system is a solution to overcome wireless sensor networks uncertainty problem [9]. Compared to non-fuzzy methods, employing fuzzy systems has many advantages: decreasing computational complexity, requiring less memory, and decreasing network development cost [6]. According to the wireless sensor network limitations and clustering, designing suitable routing methods can also improve performance and prolong lifetime in multi-hop wireless sensor networks [10].

The multi-hop (more than one hope) communications provide a consistent mechanism of communication for transferring the information in VANETs. Given the unique features of VANETs, several routing solutions have been proposed for these networks. Their main characteristics include being dynamic, high-mobility, and responsive to the network density. The network density parameter is one of the main parameters functioning to deliver the data packets to the destination. For minimum density in VANETs the routing protocols frequently desired negotiation between latency and reliability [8] Multi-hop routing has recently taken the devotion of the researchers. In this protocol, a packet is sent to all vehicles in the network in a flooding manner. Different protocols have been proposed in the recent years for the efficiency of broadcast communications and reliable transmissions that are known as smart flooding protocols [11]. The objective of presenting these procedures is to minimize the quantity of the multicast packets and an efficient use of the bandwidth in the network. Flooded transmission of the data is a protocol for sending a data packet from a source to all of its neighboring nodes. The first protocol for the flooded transmission is the simple flooding protocol [12], in which when a packet is generated and sent from a node, the receiving node rebroadcasts the packet. In order to prevent multiplier broadcasting of the same packet, each node contains a list of delivered data packets and their lifetimes. Nevertheless, this protocol leads to the multi-broadcast storm issue and the performance of the network gradually deteriorates, particularly in scenarios with a high density. Distancebased protocols are the routing protocols that use geographical data for enhancing the performance of the data rebroadcasting in the network.

There are several types of research that have been conducted for VANETs. In Reference [13], the authors suggested a Message Suppression Controller (MSC) technique for V2I and V2V communications. They dynamically control message suppression by considering some parameters; however, to calculate the time amount of message suppression, a fixed parameter is still used. Furthermore, to solve this fixed parameter problem authors suggested an Enhanced Message Suppression Controller (EMSC) [14] for (V-DTN) Vehicular-DTN the Enhanced Message Suppression Controller (EMSC) is an extended version of Message Suppression Controller (MSC) [15], which can be beneficial for different network criteria. However, the reliability and security in VANETs is very primary element to avoid unauthorized agents who may interrupt the road safety system of VANETs framework. Various researchers analyzed the disruption of traffic flows and road safety and have based their research on this serious issue. Cluster head can support in recognizing malevolent vehicles and moderate their impact by negating them to access cluster resources). Safety and security of the messages could be achieved by authentication vehicles in communication range of Road Side Unit (RSU) can be combined into one cluster to make the authentication 
process faster and a head cluster is used to verify that all the vehicles of Road Side Unit (RSU) available into the same cluster. Cluster formation in dynamic-VANET (D-VANETs) and head cluster selection mechanism play a very important role. We propose a method to compute the complexity of head cluster selection base on the following parameters: (i) direction of vehicle, (ii) degree of connectivity, (iii) an entropy threshold computed from the mobility of devices (nodes) in network, and (iv) level of distrust calculated based on the node's reliability, vehicles are allocated verifiers who are neighbors with having minimum distrust value. The verifiers used to pursue the vehicle's network control and ensure whether or not it is routing packets, advertising mobility by comparing the data of traffic messages with the verifier's neighborhood. The distrust value of devices (nodes) who act unsatisfactory is then increasing continuously; however, those nodes who perform reliably decrease continuously. Thorough this mechanism the reliability of a node is computed for the selection of head cluster process. Fuzzy logic is a primary method of reasoning logic which results approximate rather than fixed and exact. Fuzzy logic is very important in real life also it inherit facts that most modes of human reasoning and sense of common reasoning are the approximate in nature. Fuzzy logic also uses variables in linguistic nature to define the parameters. A simple expression written in linguistic can describe the understanding of a very difficult problems. The further advancement of this paper is as follows:

(i) We propose a new mechanism for broadcasting data in VANETs based on few expectations, and it is very easy to implement in distributed approach.

(ii) We also compare our method with different research in the literature based [7-9] on a connected cover set that helps to optimize the near-optimality, Time to Live (TTL), overhead, and aggregation of suggest method.

(iii) The Contention-Based-Forwarding (CBF) method is also compared with proposed, which is also standardized by European Telecommunications Standards Institute (ETSI) bodies, with name evolution as Energy-Efficient Fuzzy Management (EEFM) with IoT in VANET of proposed method is measured much better in terms of capability and to minimize the quantity of involved vehicle nodes.

\section{Related Work}

This section briefly introduces IoT, fog computing, and edge computing as enabling technologies for the full deployment and management of VANET applications and services. The expected points of many of these approaches support multiple rounds of data to roadside unit and constantly includes clustering in every round of single-hop data transmission toward the road side unit, however, the clustering in every round maximize the number of control messages and there could be the possibility of collision and decreases network energy. Multi-hop transmission prolongs cluster head node's lifetime and boosts the network's efficiency. Accordingly, this article proposes a new fuzzy clustering-based routing algorithm to benefit from multi-hop transmission clustering simultaneously Moreover, we provide a short description of VANETs in terms of the coordination of the computing resources as well as several research papers relevant to this work.

\subsection{IoT Architecture}

The IoT has become one of the most popular networking concepts that can bring out many benefits by creating a smart environment, which will permit the collection of information from the environment and make the daily life more convenient by helping people make tough decisions. For that to happen, a high interaction between people, objects, processes and services must be guaranteed [16]. While there will be a significant increase in the number of deployed devices within the environment, there should be a scalable infrastructure to enable sufficient and full utilization of available resources to take advantage of the IoT. Smart transportation and smart cities are the most important applications of IoT based in VANETs. They include intelligent traffic management in which data from the smart traffic light nodes and traffic information center infrastructures 
could be reachable by any vehicle, at any point and at any time. Such applications are delay-sensitive and require mobility support, and to satisfy these demands, the use of fog computing was proposed [17].

Fog computing is a highly virtualized platform that provides compute, storage, and networking services between end devices and traditional Cloud computing data centers offering low latency and location awareness, geographical distribution, mobility support, interoperability, and real-time interactions [2]. These attributes make fog computing the appropriate platform that meets all VANET scenarios' requirements [5,6]. However, as the number of vehicles increases, so does the amount of data generated by these vehicles. Therefore, Cloud computing still has an important role when it comes to big data management and analytics. As more and more sensors are installed on modern vehicles, massive amounts of data are generated from monitoring the on road and on-board status [18]. If those data are sent back across a long network link, to be analyzed, logged, and tracked, that takes much more time than if the data are processed at the edge, close to the source of the data [19]. Vehicles, which are equipped with networking capabilities, powerful computing units, and large storage devices, will try to process the data, and if not capable, they will seek to use the resources of adjacent vehicles. This becomes crucial, in particular, when a connection vehicle-fog server cannot be established, as well as when the fog servers where vehicles are trying to get services are overloaded. Edge computing can help monitor the massive traffic flow from the core networks and an efficient content distribution [20].

\subsection{IoT Protocols for IoT in VANET}

In the following we will briefly describe the most frequently used protocols for Machine-to-Machine (M2M) communication. The Message Queue Telemetry Transport (MQTT) is a Client Server that publishes or subscribes messaging transport protocol. It is light weight, open, simple and designed so as to be easy to implement. The protocol runs over Transmission Control Protocol/ Internet protocol (TCP/IP) or over other network protocols that provide ordered, lossless, bi-directional connections. The MQTT features include the usage of the publish/subscribe message pattern which provides one-to-many message distribution, a messaging transport that is agnostic to the content of the payload. Furthermore, the MQTT protocol has minimized transport overhead and protocol exchange to reduce network traffic and has an extraordinary mechanism to notify interested parties when an abnormal disconnection occurs as well [21].

The Constraint Application Protocol (CoAP) is a specialized Web transfer protocol for use with constrained nodes and constrained networks. The nodes often have 8-bit microcontroller with small amounts of Read Only Memory (ROM) and Random Access Memory (RAM), while constrained network often have high packet error rate and typical throughput is $10 \mathrm{kbps}$. This protocol designed for M2M application such as smart city and building automation. The CoAP provides a request and response interaction model between application end points, support build-in discovery services and resources, and includes key concepts of the Web, such as Universal Resources Locator (URls) and Internet media types. CoAP is designed to have a friendly interface with Hypertext Transfer Protocol (HTTP) for integration with the Web, while meeting specialized requirements such as multicast support, very low overhead and simplicity for constrained environments. On the other side, many people will still be driving even on the era of autonomous cars. The high cost of driverless cars, lack of trust and not wanting to give up driving might be among the reasons why those people will continue to drive their cars. Hence, many researchers and automotive engineers keep working on Driver Assistance Systems (DASs) and Driver Monitoring System (DMSs) as a primary safety feature required in order to achieve full marks in safety. DASs and DMSs are intelligent systems that reside inside the vehicle and help the driver in a variety of ways. These systems rely on a comprehensive sensing network and artificial intelligence techniques, and have made it possible to commence the era of connected cars. They can invoke action to maintain driver attention in both manual and autonomous driving. While the sensors are used to gather data regarding the 
inside/outside environment, vehicle's technical status, driving performance and driver's condition, the intelligent systems task is to make decisions based on these data. If the vehicle measurements are combined with those of the surrounding vehicles and infrastructure, a better environment perception can be achieved. In addition, with different intelligent systems located at these vehicles as well as at fog servers more efficient decisions can be attained. Substantial research has been done over the years to build and improve DASs and DMSs. Many big automotive companies such as Toyota, Nissan, Mercedes-Benz, BMW, Volvo, and Saab, as well as third parties including Seeing Machines, Veoneer, and Smart Eye, are conducting continuous research to develop such intelligent systems.

\subsection{Cluster Protocol in VANET}

This component defines few clustering algorithms of Hypertext Transfer Protocol (Wireless sensor networks WSNs), and their advantages and disadvantages are studied. Hypertext Transfer Protocol (LEACH) [22] is a self-organizer clustering protocol that uses cluster based hierarchical routing to distribute an energy load on network devices. In this algorithm, the role of the cluster head is played by all existing nodes in each round in order to achieve uniform energy consumption. LEACH algorithm has two stages: 1-setting up stage 2-stable stage. In the first stage, clusters are formed and in the stable stage, communications are directed to cluster head sent to the roadside unit after being received and aggregated. For each node, the value between 0 and 1 is computed in the first round, if the computed value is less than the specified value (called threshold) for a node and is considered a head cluster. Ignoring "node residual energy" in selecting the cluster head and random selection at beginning of each round are the weak points of this algorithm. Distributed load balancing unequal clustering using fuzzy approach (DUCF) [23] is a clustering algorithm-based o fuzzy system. In this algorithm criteria such as "residual energy", "node grade" and "each node distance to the road side unit" are used to form the cluster. In DUCF, unequal clustering is used to yield balanced energy consumption. Using imbalanced clustering and FSs (fuzzy systems) is said to be the advantage of this method. The disadvantages are to select head cluster in very round which leads to maximize consumption of energy. Multi-objective fuzzy clustering algorithm (MOFCA) [24] is an extra clustering algorithm based on fuzzy system. This algorithm is presented to solve "energy hole" and "hotspot" problems. In this method "residual energy", "distance to road side unit," and "node density" are all used as fuzzy parameters, and in the starting of every round, random head clusters are selected. The selection of head cluster in this method is according to energy-based competition radius. Using unequal clustering in this algorithm causes balanced energy consumption, which is considered an advantage, and clustering in each round is taken to be a disadvantage.

Energy aware unequal clustering fuzzy (EAUCF) [25] is another clustering method presented to increase a network's lifetime. This algorithm is based on fuzzy system in which "residual energy" and "distance to road side unit" are used as fuzzy parameters. In order to improve previous methods' performances, a complete probable approach is not used for node selection, and periodic exchange of cluster head role among the nodes is done using fuzzy system. This algorithm increases lifetime in static networks, but it is not suitable for dynamic ones [26]. One weak point of this algorithm is that clusters must be estimated before clustering, making the algorithm complicated. Another problem in EAUCF method is ignoring "node density" as a parameter in cluster head selection. As a result of this, a node with few neighbors might be selected as the cluster head. Stability can be considered as one of the advantages of this algorithm. The EAFCA algorithm [27] is presented to improve clustering in wireless sensor networks. In this algorithm, data transmission inside each cluster is done in a multi-hop way, and the competition radius for each cluster is considered to be equal to two hops. It uses "residual energy", "node density", and "centralization degree" for cluster head selection. Considering communications inside the cluster in a multi-hop way is one of the advantages of this method. In this algorithm, clustering is done in every round, which increases the quantity of sent control messages 
and decreases the lifetime. The FLECH algorithm [28] is a hierarchical clustering algorithm based on fuzzy system. In this algorithm, "residual energy", "centralization degree", and "distance to road side unit" are used to elect the cluster head. Cluster head selection in this method is a combination of weighted and probable approaches that can be considered as an advantage. Clustering in each round is one of the disadvantages. In Reference [29], the author proposed the fuzzy logic system to resolve the multicasting issue distribution and inhomogeneous high vehicle mobility for some section crowded/not crowded to increase the routing protocol make the dynamic decision, which consisted of three input parameters of packet advancement number of duplicate packet delivered and local density.

\section{Proposed Method}

The algorithm assumptions are given as follows:

All the vehicles (nodes) are homogenous, and they have balanced initial energy.

$>$ The vehicles (nodes) are distributed in the network randomly.

$>$ All road side units and other devices (nodes) are static.

$>$ For calculating the distance Euclidean method is used.

$>$ Road side unit receive the data by cluster head in a multi-hop way and in certain cases in a single-hop way.

$>\quad$ The nodes which are positioned inside $\mathrm{R}$ distance to a certain device are considered as its neighbors.

The energy consumption model for sending $\mathrm{L}$ bit data package from the transmitter to receiver in $\mathrm{d}$ (distance) is as follows [29]:

$$
\mathrm{E}_{\mathrm{TX}}(\mathrm{l}, \mathrm{d})=\left\{\left\{\begin{array}{c}
1 * \mathrm{E}_{\mathrm{elec}}+1 * \varepsilon_{\mathrm{fs}} * \mathrm{~d}^{2} \text { if } \mathrm{d}<\mathrm{d}_{0} \\
1 * \mathrm{E}_{\mathrm{elec}}+1 * \varepsilon_{\mathrm{mp}} * \mathrm{~d}^{4} \text { if } \mathrm{d}<\mathrm{d}_{0}
\end{array}\right\}\right.
$$

where $\mathrm{d}$ is mention for distance, $\mathrm{E}_{\text {elec }}$ is considered as the amount of energy consumption for sending every binary digit $(0,1)$ representing some sort of energy consumption to transfer data from sender to receiver, and $\varepsilon_{\mathrm{fs}}$ is for more than one route operation. Required energy (ERX) is the required energy for the receiver to receive data and is obtained from the following relation [30]:

$$
\begin{aligned}
\mathrm{d}_{0} & =\sqrt{\frac{\varepsilon_{\mathrm{fs}}}{\varepsilon_{\mathrm{mp}}}} \\
\mathrm{E}_{\mathrm{RX}} & =1 * \mathrm{E}_{\mathrm{elec}}
\end{aligned}
$$

\subsection{Symbolizations and Descriptions}

The symbolizations of this paper are defined in Table 1, below.

Table 1. Notation.

\begin{tabular}{cr}
\hline Notations & $\begin{array}{c}\text { Meaning } \\
\mathrm{CH}\end{array}$ \\
\hline $\mathrm{SCH}$ & $\begin{array}{r}\text { The cluster head node is accountable for accumulating the received } \\
\text { environmental data and sending them to the road side unit. }\end{array}$ \\
\hline $\mathrm{CHL}$ & $\begin{array}{c}\text { The leader cluster head responsible to send the accumulated data to the road } \\
\text { side unit. }\end{array}$ \\
\hline $\mathrm{BS}$ & Road side unit. \\
\hline $\mathrm{R}$ & Shows the clustering method used by the division remainder function. \\
\hline Mod(r,3) & Is used to compare two values.
\end{tabular}


Table 1. Cont.

\begin{tabular}{|c|c|}
\hline Notations & Meaning \\
\hline Criterion & Suitability criterion for each cluster head (distance/energy). \\
\hline Energy & Node residual energy at every moment \\
\hline Terminologies CM & The cluster member node responsible for receiving the environmental data. \\
\hline $\mathrm{CH}$ & $\begin{array}{l}\text { The cluster head node responsible for aggregating the received environmental } \\
\text { data and sending them to the road side unit. }\end{array}$ \\
\hline $\mathrm{SCH}$ & The substitute cluster head replaces the cluster head if there is lack of energy. \\
\hline $\mathrm{CHL}$ & $\begin{array}{c}\text { Cluster head leader is responsible for sending the aggregated information to } \\
\text { road side unit. }\end{array}$ \\
\hline BS & Road side unit. \\
\hline $\mathrm{R}$ & Number of rounds. \\
\hline $\operatorname{Mod}(r, 3)$ & Shows the clustering method used by the division remainder function. \\
\hline Compare & Is used to compare two values. \\
\hline Criterion & Suitability criterion for each cluster head (distance/energy). \\
\hline Energy & Node residual energy at every moment. \\
\hline Competition Radius & Competition radius to get the cluster head leader. \\
\hline FND & The first dead node. \\
\hline HND & Half of the dead nodes. \\
\hline LND & The last dead node. \\
\hline $\mathrm{E}_{\text {elec }}$ & Amount of energy consumption. \\
\hline$\varepsilon_{\mathrm{fs}}$ & More than one route operations. \\
\hline ERX & Required energy. \\
\hline Elex & Energy derived. \\
\hline ERC & Receiving one bit data. \\
\hline
\end{tabular}

\subsection{Fuzzy Logic System}

Geometric, coordinate points and other various methods used to measure the distance earlier. In proposed method the longitude and latitude points have been used to measure the distance of neighbors. We supposed that each vehicle is connected with GPS Global Positioning system [31]. Using GPS, we calculated the latitude and longitude points to compute neighbor vehicles' distance, according to these points among the neighbor vehicles computed. Here $\mathrm{L}_{\mathrm{A} 1}$ is the latitude point and $\mathrm{L}_{\mathrm{O} 1}$ is the longitude point of vehicle 01 noted as (V1); however, $\mathrm{L}_{\mathrm{A} 2}$ is the latitude point and $\mathrm{L}_{\mathrm{O} 2}$ is the longitude point of vehicle 02 noted as (V2). The distance between V1 and V2 was measured by using $\mathrm{D}=\mathrm{R}^{*} \mathrm{C}$ notation, where $\mathrm{R}$ denotes the circle radius and $\mathrm{C}$ is computed as the range of center of radius equal to the distance between two points.

\subsubsection{Speed}

Data transmission can be interrupted by the speed of the vehicle in VANET, and it can cause dynamic topology changes in VANET. We supposed that every vehicle is connected with the speedometer of the vehicle to measure the speed of the vehicle in VANET [32].

\subsubsection{Link Residual Time}

Link Residual Time (LRT) is the time duration of vehicles when vehicles are in the communication range. The LRT is calculated by using a physical layer and distance parameters [33] like receiver power, transmission power and SNR signal-to-noise ratio. We can also optimize the efficiency of data transmission by using these LRT [34], where SNR0 
is the received signal and noise ratio, SNRth is the threshold value of signal-to-noise ratio, $\mathrm{d}$ is the distance, and $\lambda$ is the path loss.

$$
\mathrm{LRT}=\frac{\sqrt{10^{\left(\mathrm{SNR}_{0}-\mathrm{SNR}_{\mathrm{th}}\right) / 5 \lambda}-d}}{\text { Relativespeed }}-\left(\mathrm{t}_{1}-\mathrm{t}_{2}\right)
$$

The FLS (fuzzy logic system) contains main three parts: (i) fuzzy logic engine, (ii) fuzzifier, and (iii) defuzzifer. The fuzzification system receives three input parameters, namely speed, distance, and LRT (Link Residual Time). We used the member function, which is responsible for converting input data into fuzzy logic data. The value of distance in member function is \{less, Medium, High\}, the value of speed in member function is \{slow, Medium, High\}, and the value of LRT in member function is \{Poor, Good, Average\}. The member functions are defined inside triangular functions with value ranges between 0 and 1 [35].

\section{Algorithm and Model}

The fuzzy sets model gradual properties to model a theoretical possibilities matter the degree of satisfaction, and the data provided with uncertainty and imprecision allows them to be used in a vast variety of applications. The fuzzy control (FC) is the most famous application. The industrial applications since the appearance are the domestic appliances, process control, and automotive systems from the multiple other fields [36] shown in Figure 1.

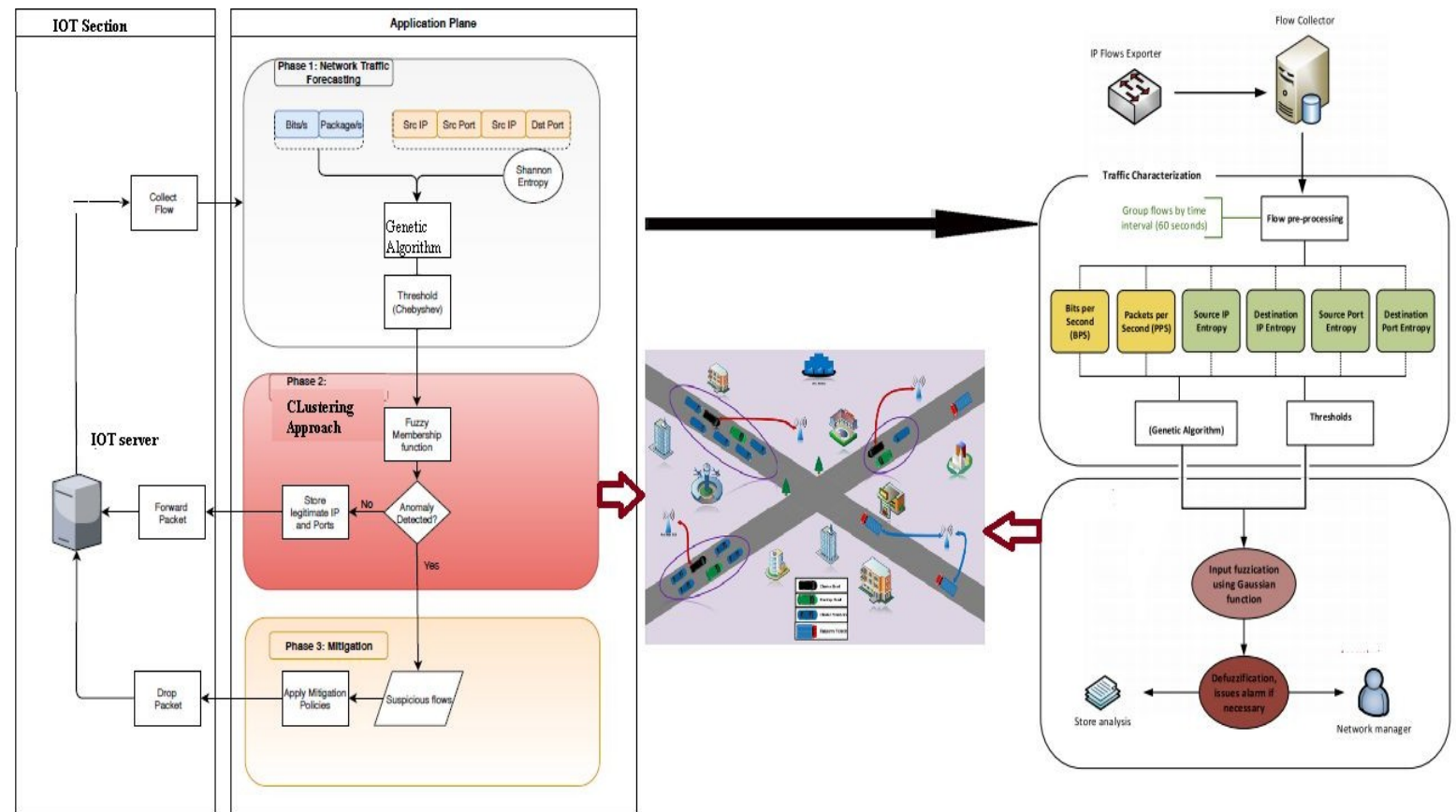

Figure 1. This is a figure. Schemes follow the same formatting.

\subsection{Fuzzy Control in the Fuzzy Control Systems}

The knowledge based expert is encoded fuzzy rules mechanism which helps to decide specific operation(s) for different modules of environment which represented by FS. The fuzzy control methodology also allows to model any type of control law which depend upon some sort of conditions that this law can be defined as "if ... . then ...." set of rules as in expert systems case. The fuzzy logic diverges from approach called SES Standard Expert System with mechanism called interpolation. According to the complex processes approach, it can be helpful to get more knowledge based on practical and expert operators rather than to compute optimal control [37-39]. 


\subsection{Linguistic Variables}

A central idea of fuzzy logic that plays a very important role in the application of fuzzy logic is linguistic variable. Multiple numerical values can be represented by a single linguistic variable therefore it is so called the form of a data compression. It is recommended to suggest to use and refer linguistic variable data compression form [40]. Similar results can be achieved using conventional quantization since in this case of quantization the interval values are used however in the other hand granulation the overlapping values are used in fuzzy sets. The strangeness of granulation then quantization are as follows: (i) it is generalized, (ii) it provides the way to compile linguistic values, and (iii) transition of linguistic value from or to contiguous linguistic value is more gradual than abrupt, and the performance is more robust.

\subsection{FC Rules}

Fuzzy control explores an algorithmic approach for the process control between data and rules(conditions), which can control the process. Here we supposed variables $i, j$ as input variables and $\mathrm{k}$ for the out of the process. Here we used control algorithm's rules in expression like "if ... then ... "; likewise, if I is less and $\mathrm{j}$ is greater than $\mathrm{k}$ is average; if $\mathrm{I}$ is greater and $\mathrm{j}$ is average then $\mathrm{k}$ is greater; these conditional rules are termed as fuzzy control rules. The "if" section of rule set is known as the antecedent and the "then" section of rule set is known as the consequent. As we defined that $I$ and $j$ variables are used as input and $\mathrm{k}$ is the output variable [39]. The values "less", "greater", and "Average" are called fuzzy values of $i$ and $j$; however, they are mapped by FS fuzzy sets. Fuzzy controllers are the set of rules which receives the input of $I$ and $j$ variables and based on those input variables the output is computed through the fuzzy interface [40].

\subsection{Control Knowledge Base}

While designing the control knowledge base (CKB), the two main parameters must be considered first, the linguistic variable set that describes the values for the whole process's major parameters. Here both input, as well as output parameters, must be expressed in the form of linguistic variable definition by using complete and clear term sets. In the smoothness of process control, granularity selection of an input and output variables plays an important role. Secondly a mechanism of control knowledge base is very primary to develop for using the input and output linguistic parameter's description. Four different methods have been suggested for achieving this [41-45]: self-organization, modeling of operator's control operation, expert's experience and knowledge, and modeling a process. From the methods discussed above, the third one is the most widely used method. In the third method, called expert operator's knowledge, the fuzzy rules of the form "If Error is small and Change-in-error is small then the Force is small" used in various research studies [46-48]. This method performs more efficiently when human expertise is used to express the knowledge base heuristic to control the process in the form of linguistic variable.

\subsection{Defuzzification Methods}

The operation termed as defuzzification operation generates a non-fuzzy control action which show the member function for an inferred fuzzy control action. Different defuzzification approaches have been found in the literature out of them the four different methods have been selected to often apply here: (1) Center of Area (COA), (2) Tsukamoto's Defuzzification Method (TDM), (3) Mean of Maximum Method (MOM), and (4) Defuzzification once Output of Procedures functioning as inputs in Algorithms 1 and 2. 

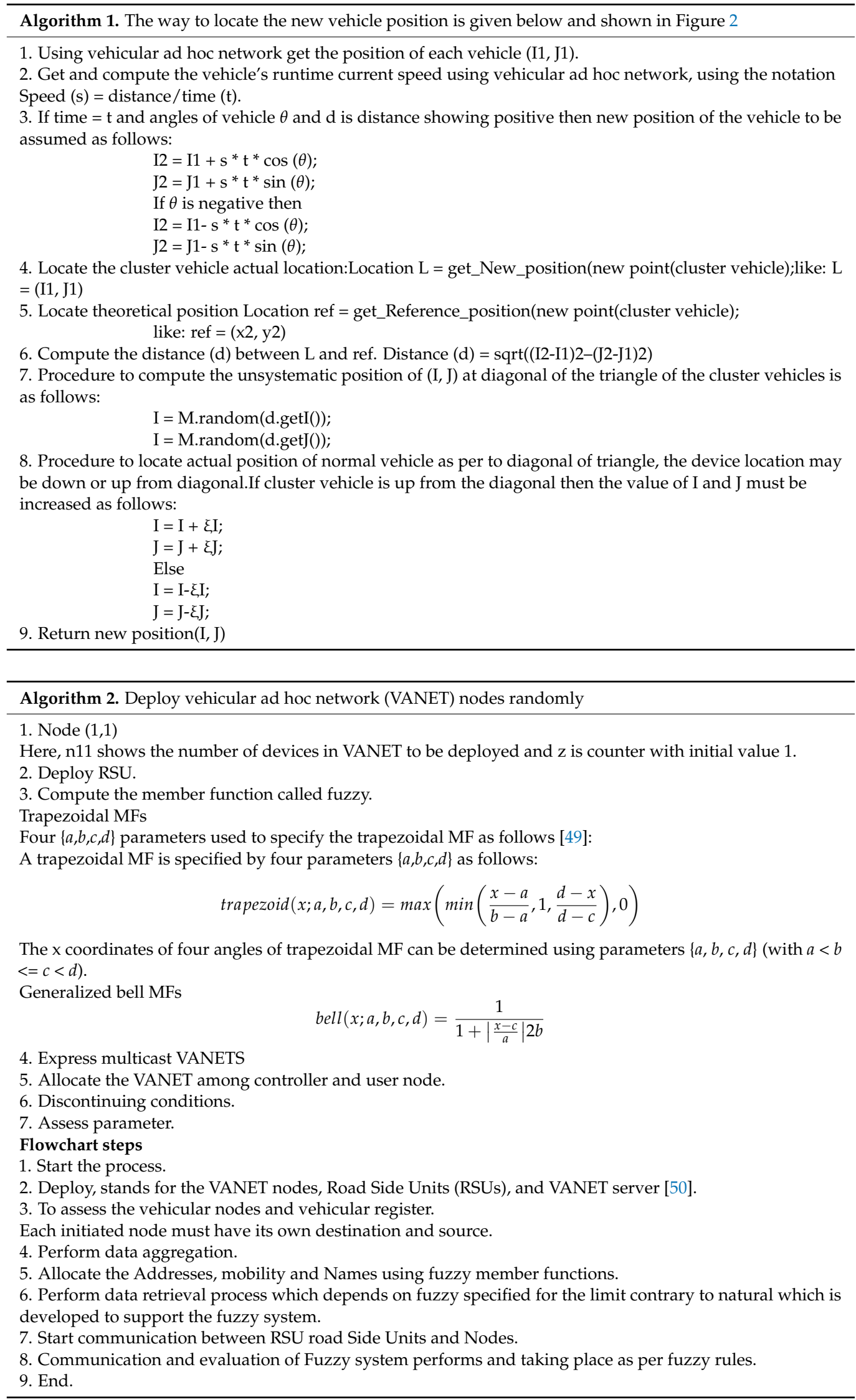


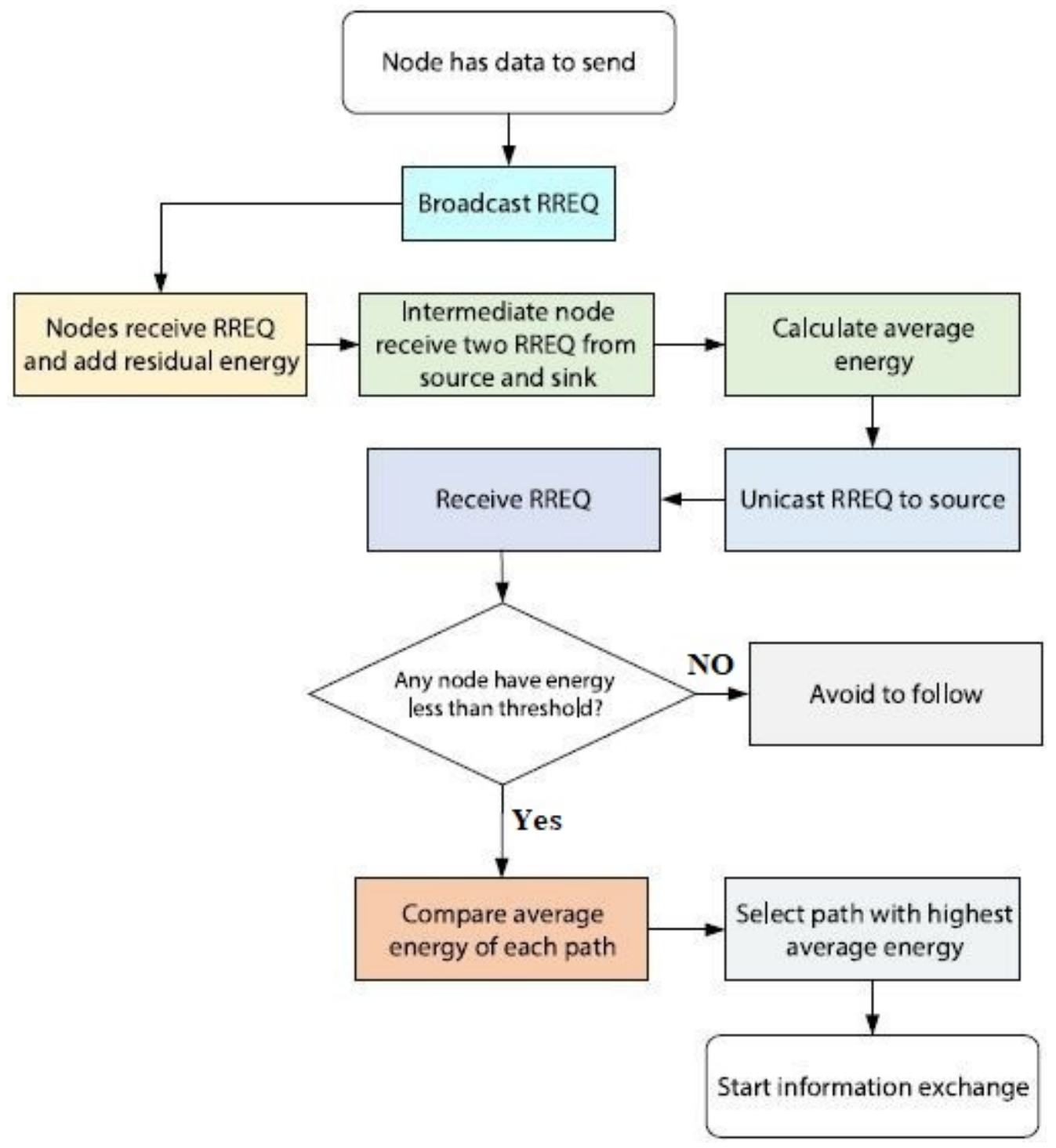

Figure 2. System diagram of path selection.

\section{Experimental and Evaluation}

For performance evaluation of suggested system and for comparison with existing systems, we utilized the software simulator tool named NS-2 [51]; in Table 2, the suggested system is evaluated with different significant challenges such as $\mathrm{CH}$ duration, Average, Stability convergence, cluster member, control overhand by speed and vehicle, energy consumption and throughput of various parameters. Secure Stable-CA [51-57] and MothFlame-CA [58] were used to perform the comparison of stab Trust. Once the operation on different elements of trust, the value of stab Trust is between 0.0 to 1.0. This simulation is integrated with Simulation Urban Mobility (SUMO) for evaluation of runtime environment. For the simulation, we arrayed 10,000 different nodes randomly in the distance of $200 \mathrm{~m}$, and IEEE 802.11 standard protocol was used for medium access [59] with the transmission speed of $8 \mathrm{Mbps}$. The remaining parameters are shown in Table 2 . Whole simulation was implemented with different types of vehicles which enter through different entry points and meet other vehicles' genetic algorithm for training the behaviors and patterns of traffic network, using unsupervised machine learning method. 
Table 2. Simulation parameters.

\begin{tabular}{ccc}
\hline Process & Parameters & Value \\
\hline Flow preprocessing & Number of weeks used to analysis & 8 \\
\hline & Interval time & 1 min \\
\hline Traffic & Fitness function & Distance, speed and time \\
\hline & Number of generations & 10,000 \\
\hline & Number of vehicle & Two way \\
\hline
\end{tabular}

Additionally, it has the features to deal with reservations available in traffic network data because it also has soft computing characteristics. The numeric chromosome encoding method is used in proposed system. However, the binary encoding method is commonly used method since the runtime value encoding is primarily applicable, as shown in Figure 3. Evaluation of fitness as per time intervals [60-66]. Furthermore, the tributes are considered as numeric values in this case it is not mandatory to encrypt and decrypt binary digits into numeric or any other type of values. Here every chromosome is said to be a single value (numeric) for every property rather than considering whole values as time intervals or all properties as chromosome. We supposed two reasons to follow this encoding process: (1) Every time interval could be elevated uniquely with the analysis of real time, and (2) every attribute could be elevated in parallel form, which speeds up the analysis process. Due to chromosomes encoding numerically arithmetic operations used to implement the crossover and mutation operations, the output of chromosome after crossover operation is the average of a particular chromosome. The mutation operation can affect the chromosomes value as $1 \%$ chances of subtraction and 3\% chances of adding in/from the current value of chromosome. If the change is in small value portion, then the technique works for multiple solutions. It was perceived that the maximum mutation can lead to delay the evaluation mechanism due to non-convergence values of chromosomes. Every interval's superior and interior limits are computed to create essential population values that are very close to optimal point. To generate a greater number of creations, the genetic actions of mutation, crossover and selection are performed. The function called fk is used to assess the creation of chromosomes in Euclidean distance among chromosomes and every component of input variable [67-77]. 


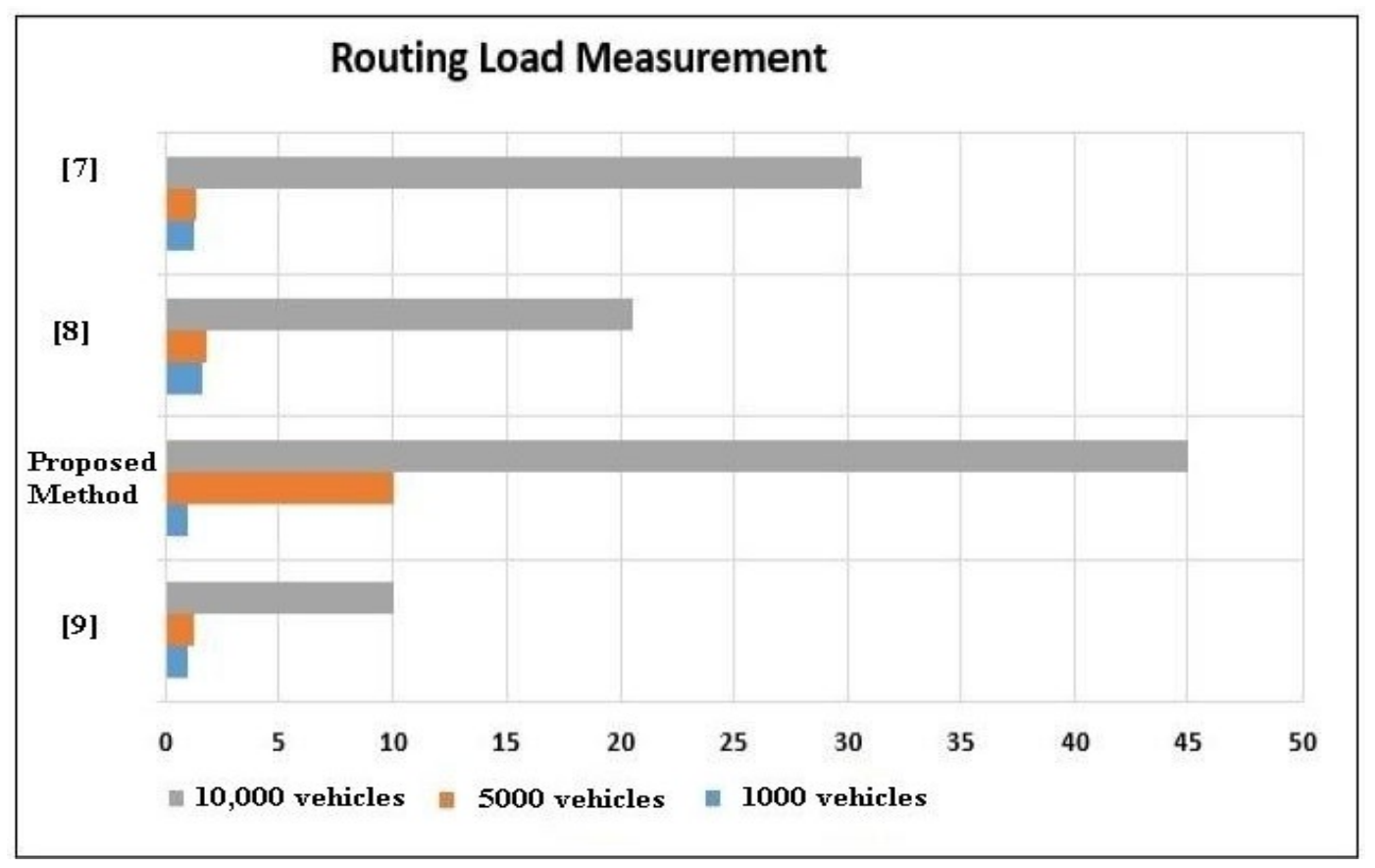

Figure 3. Routing load measurement (RLM).

\section{Performance Results}

We show the simulation-based results computed using and fuzzy-IoT, two fuzzy, Fuzzy-Based Driver Monitoring System (FDMS) the vehicle speed (VS), which has been considered a fixed parameter. The relation of fuzzy-IoT, two fuzzy, and FDMS for various values is shown Figure 3 shows the simulation based results with the value of VS as 50 . The proposed method goes to its highest value, which is 50, as compared to fuzzy-IoT, two fuzzy, and FDMS; for this specific value, the vehicle speed and velocity are the same as other clusters' vehicles. The vehicles leave the cluster if the vehicle moves faster or slower velocity than the other vehicles [78-83]. The possibilities of vehicle to reside inside the cluster are more when the value of Fuzzy-IoT is increased. In Figure 3, the value of VS is considered 50 and 100 accordingly. When the value of VS increases the value of fuzzy-IoT, two fuzzy, FDMS is increased automatically, which shows that this vehicle possesses more chances to remain inside the cluster because it is considered more secure. Figure 4 also shows the proposed simulation results. Comparing our method Figure 5 with the results, we can see that the proposed method have less delay than other methods could have more possible chances for remaining inside the cluster. Thus, the vehicles are traveling with the same speed and velocity as other clusters' vehicles are traveling, have high connectivity, and have high security and trustworthiness (Table 3). 


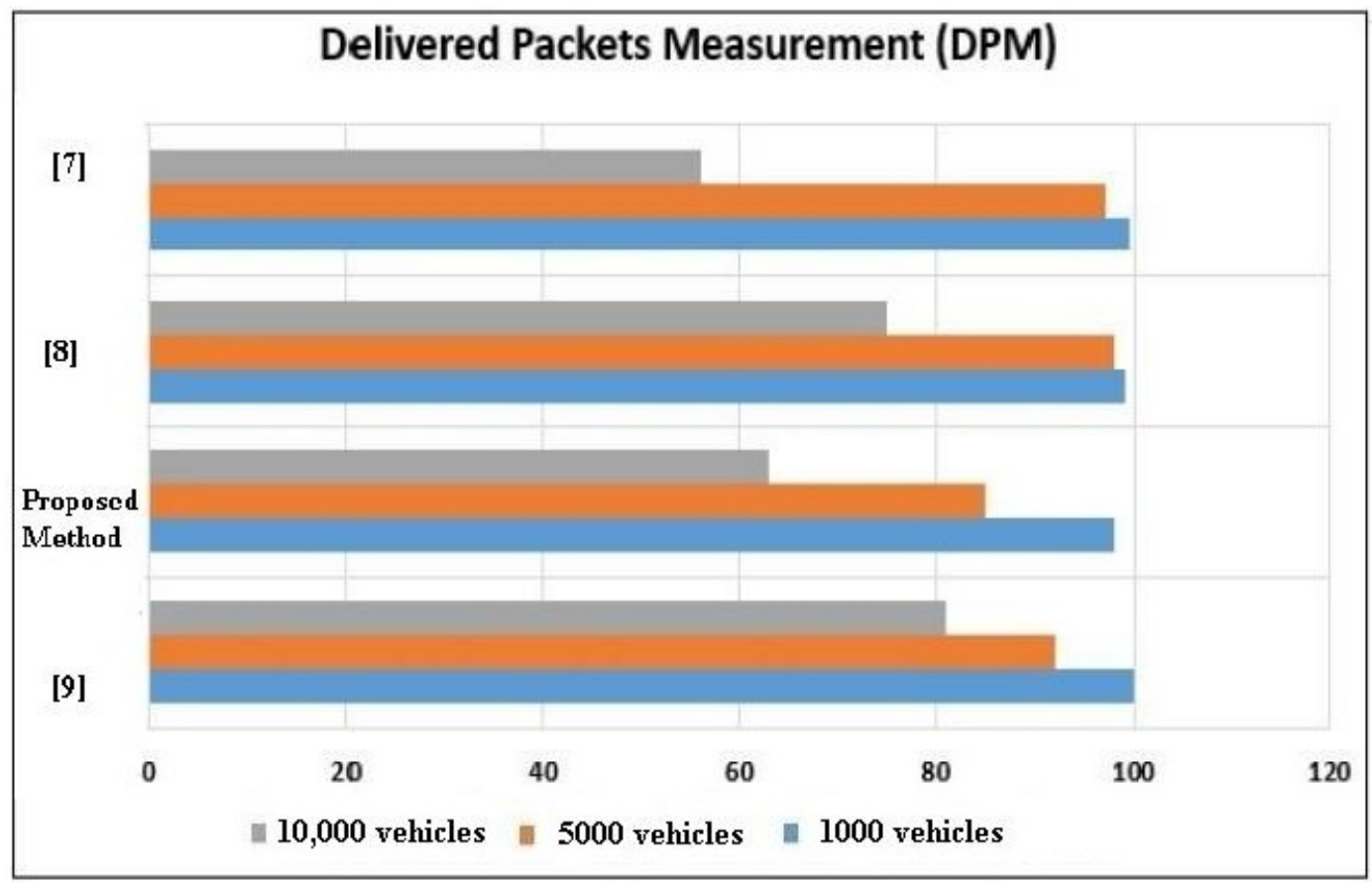

Figure 4. Delivered packets measurement (DPM).

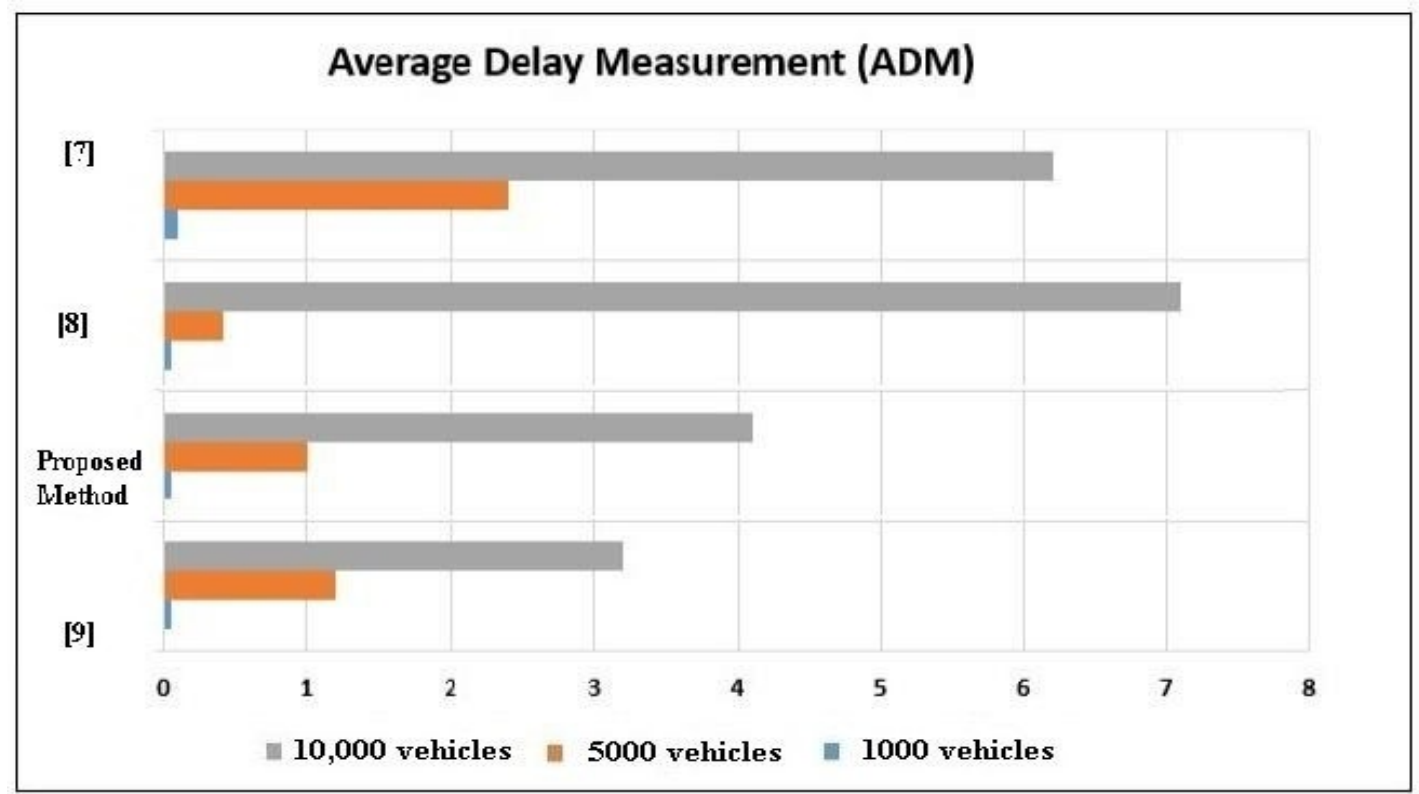

Figure 5. Average delay measurement (ADM). 
Table 3. Fuzzy logic rules.

\begin{tabular}{|c|c|c|c|c|c|c|c|}
\hline Rule & Distance & Speed & LRT & $\begin{array}{l}\text { Packet Ad- } \\
\text { vancement }\end{array}$ & $\begin{array}{c}\text { Number of } \\
\text { Duplicate } \\
\text { Packets }\end{array}$ & Density & Rank \\
\hline $\mathrm{R} 1$ & Less & Slow & Poor & Close & Low & Low & Accept \\
\hline $\mathrm{R} 2$ & Less & Slow & Average & Close & Medium & Low & Accept \\
\hline $\mathrm{R} 3$ & Less & Slow & Good & Close & High & Low & $\begin{array}{l}\text { Highly } \\
\text { accept }\end{array}$ \\
\hline $\mathrm{R} 4$ & Medium & Slow & Poor & Close & Low & Medium & Reject \\
\hline R5 & Medium & Slow & Average & Close & Medium & Medium & Accept \\
\hline R6 & Medium & Slow & Good & Close & High & Medium & Accept \\
\hline R7 & High & Slow & Poor & Close & Low & High & Reject \\
\hline $\mathrm{R} 8$ & High & Slow & Average & Close & Medium & High & Reject \\
\hline R9 & High & Slow & Good & Close & High & High & Accept \\
\hline R10 & Less & Medium & Poor & Intermediate & Low & Low & Accept \\
\hline R11 & Less & Medium & Average & Intermediate & Medium & Low & $\begin{array}{l}\text { Highly } \\
\text { accept }\end{array}$ \\
\hline R12 & Less & Medium & Good & Intermediate & High & Low & Reject \\
\hline $\mathrm{R} 13$ & Medium & Medium & Poor & Intermediate & Low & Medium & Accept \\
\hline R14 & Medium & Medium & Average & Intermediate & Medium & Medium & Accept \\
\hline R15 & Medium & Medium & Good & Intermediate & High & Medium & Reject \\
\hline R16 & High & Medium & Poor & Intermediate & Low & High & Reject \\
\hline R17 & High & Medium & Average & Intermediate & Medium & High & Accept \\
\hline R18 & High & Medium & Good & Intermediate & High & High & Accept \\
\hline R19 & Less & Fast & Poor & Far & Low & Low & $\begin{array}{l}\text { Highly } \\
\text { accept }\end{array}$ \\
\hline $\mathrm{R} 20$ & Less & Fast & Average & Far & Medium & Low & Accept \\
\hline R21 & Less & Fast & Good & Far & High & Low & Accept \\
\hline $\mathrm{R} 22$ & Medium & Fast & Poor & Far & Low & Medium & $\begin{array}{l}\text { Highly } \\
\text { accept }\end{array}$ \\
\hline $\mathrm{R} 23$ & Medium & Fast & Average & Far & Medium & Medium & Reject \\
\hline $\mathrm{R} 24$ & Medium & Fast & Good & Far & High & Medium & Accept \\
\hline $\mathrm{R} 25$ & High & Fast & Poor & Far & Low & High & Accept \\
\hline R26 & High & Fast & Average & Far & Medium & High & Reject \\
\hline $\mathrm{R} 27$ & High & Fast & Good & Far & High & High & Reject \\
\hline
\end{tabular}

Figures 3-5 illustrate the comparative study of three different approaches with mobility based model called EEFM with IoT in VANET based on average delay measurement (ADM), delivered packets measurement (DPM) and routing load measurement (RLM). The comparative results represent the satisfactory performance of mobility models in VANET [72-75].

We also optimized the parameter of trustworthiness in the proposed system, in this regard we reflected the VS and vehicle time (VT) as fixed parameters Tables 4-6 in this table we fixed value 10 in this case if VT and CS both are 10. The vehicle has to leave the cluster, this define that if any vehicle has low security and low trustworthiness has to leave the cluster even the vehicles are traveling in same speed as other vehicles are traveling. 
Table 4. Overhead.

\begin{tabular}{ccc}
\hline Vehicle Speed & Overhead [7] & Overhead (Proposed Method) \\
\hline 10 & 3.0005 & 2.0007 \\
\hline 30 & 4.5145 & 2.9005 \\
\hline 50 & 5.6457 & 3.4578 \\
\hline 80 & 7.6654 & 5.6700 \\
\hline 100 & 9.5287 & 8.5550 \\
\hline 120 & 11.8322 & 10.2301 \\
\hline 150 & 15.6548 & 14.2305 \\
\hline 180 & 17.7630 & 15.7843 \\
\hline 200 & 21.3064 & 16.6897 \\
\hline 220 & 22.6530 & 18.4601 \\
\hline
\end{tabular}

Table 5. Aggregation time.

\begin{tabular}{ccc}
\hline Vehicle Speed & Aggregation [7] & Aggregation (Proposed Method) \\
\hline 10 & 0.6788 & 0.3457 \\
\hline 30 & 1.2397 & 0.5543 \\
\hline 50 & 1.6867 & 0.8856 \\
\hline 80 & 1.9788 & 1.0657 \\
\hline 100 & 2.0227 & 1.3887 \\
\hline 120 & 3.4229 & 2.1974 \\
\hline 150 & 4.2547 & 2.2647 \\
\hline 180 & 4.6934 & 2.5974 \\
\hline 200 & 4.9781 & 2.6971 \\
\hline 220 & 5.2345 & 2.9615 \\
\hline
\end{tabular}

Table 6. Time to Live (TTL), in seconds.

\begin{tabular}{ccc}
\hline Vehicle Speed & TTL [7] & TTL (Proposed Method) \\
\hline 10 & 0.6077 & 0.5492 \\
\hline 30 & 2.5187 & 2.0478 \\
\hline 50 & 3.1092 & 3.1579 \\
\hline 80 & 3.9972 & 3.3497 \\
\hline 100 & 4.5277 & 3.6837 \\
\hline 120 & 4.8231 & 4.1938 \\
\hline 150 & 5.2098 & 4.3423 \\
\hline 180 & 5.5974 & 4.7647 \\
\hline 200 & 6.0973 & 5.0742 \\
\hline 20 & 6.7814 & 5.5491 \\
\hline
\end{tabular}

(1) Overhead

Here overhead is illustrated by using the set of additional or even oblique period of computation, data transfer speed, storage, and a few other features that are mandatory to be considered for achieving specific output. As shown in Table 4, it is assumed that the 
control overhead technique has achieved significant results rather than the other techniques reviewed in the literature.

The comparative results of control overhead among the proposed method and existing is shown in Figure 6 . Here the $x$-axis illustrates the speed of vehicles, and the $y$-axis shows the time value. In the case of the proposed system, overhead is compared as lower than [7].

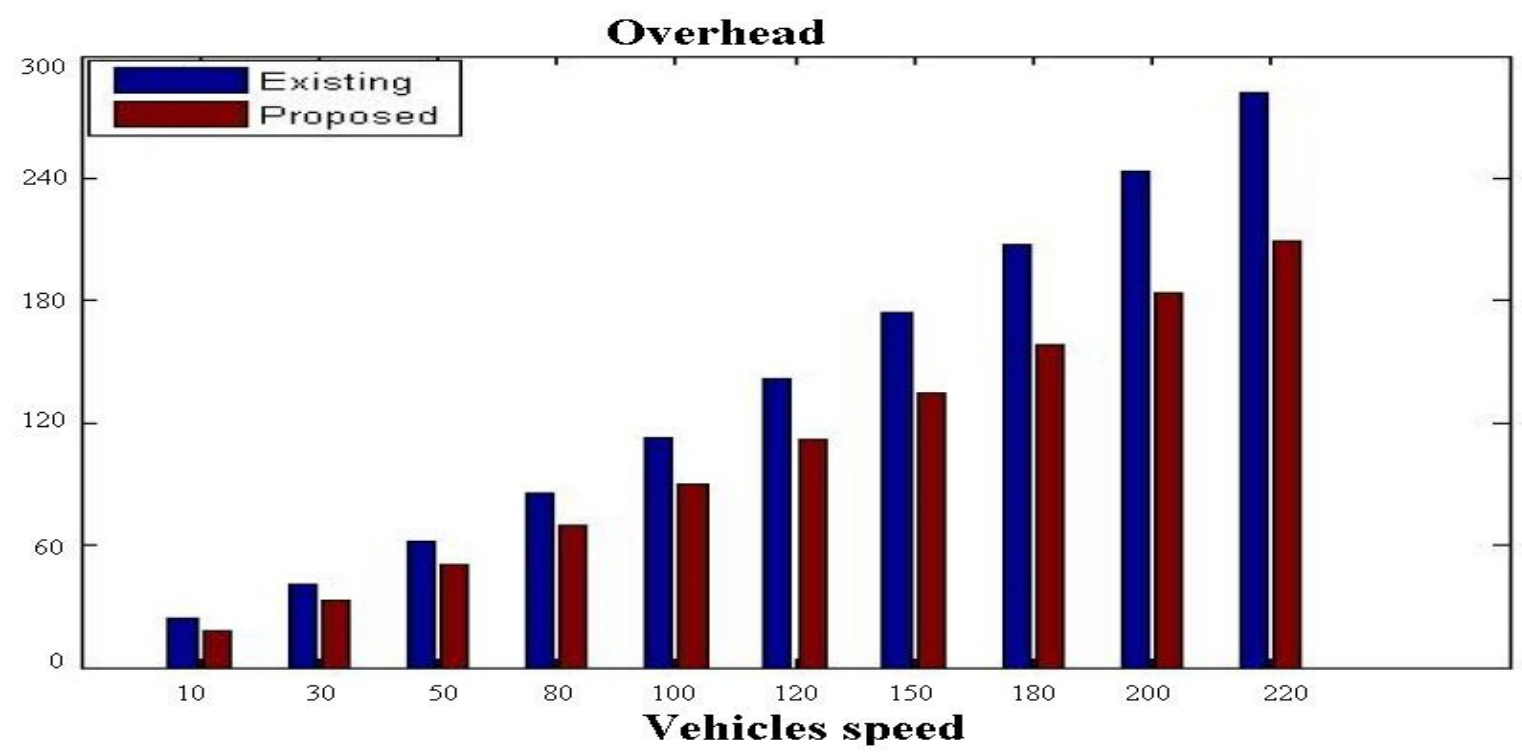

Figure 6. Overhead (seconds).

(2) Aggregation Time

Aggregation time is time period which consumed to aggregate the data. Basically it combines very close and similar data details which could be sent via unique nodes. As shown in Table 5, it is desirable to decrease the data volume before sending them. The comparative results show the better performance of proposed data aggregation time then the existing techniques found in the literature [7].

The comparative result of aggregation time of proposed method and existing method is shown in Figure 7, where the $x$-axis illustrates the speed of vehicles, and the $y$-axis illustrates the time. The comparative results show the better performance with lower numeric values of proposed data aggregation time than the existing techniques found in the literature.

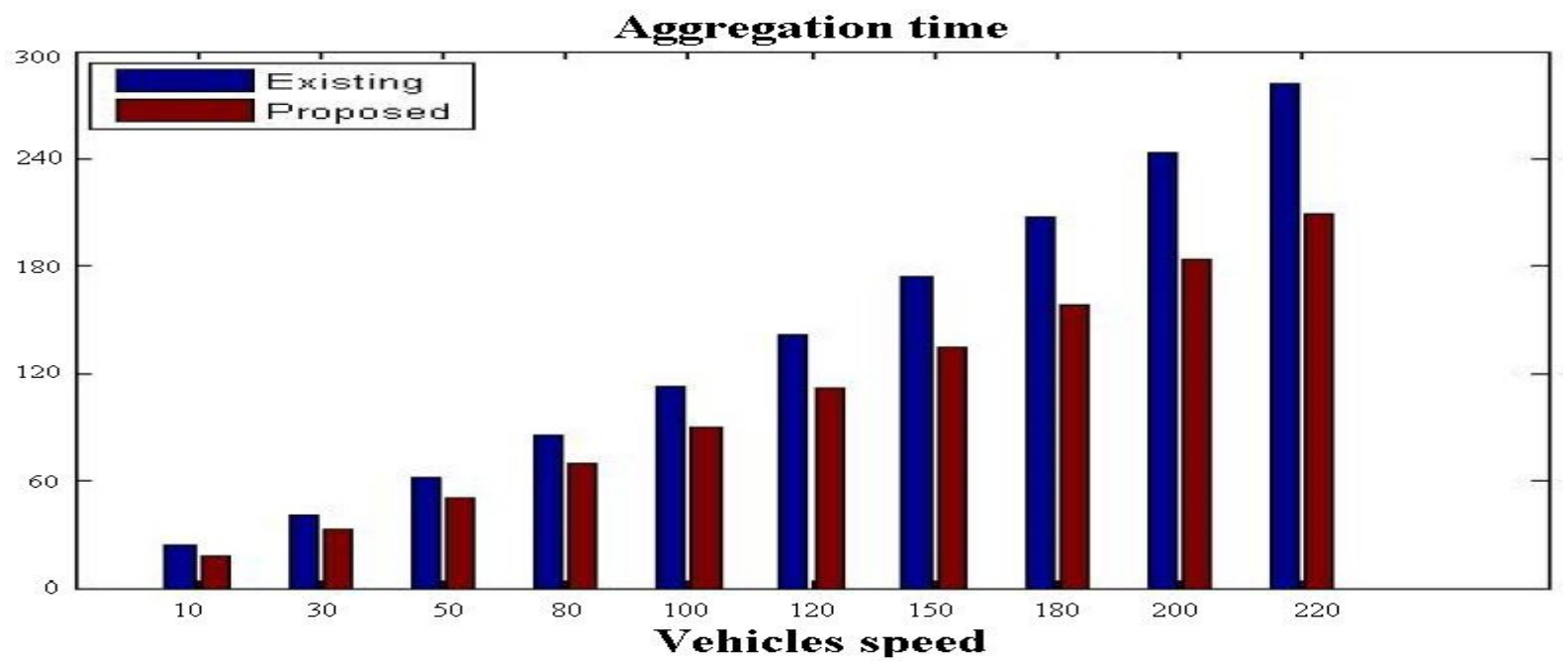

Figure 7. Aggregation time (seconds). 


\section{(3) Time to Live}

A mechanism which limits this lifecycle and duration of facts during computer network is known as TTL (Time to Live). This Time to Live is also considered as timestamp embedded and mounted on this data. When the feature called timestamp is elapsed then the data details are automatically discarded. TTL is acquainted for performance and privacy increment as shown in Table 6.

The comparative result of Time to Live (TTL) of proposed method and existing method is shown in Figure 8, where the $x$-axis illustrates the speed of vehicles, and the $y$-axis illustrates the time. The comparative results show the better performance with lower numeric values of proposed Time to Live (TTL) than the existing techniques found in the literature.

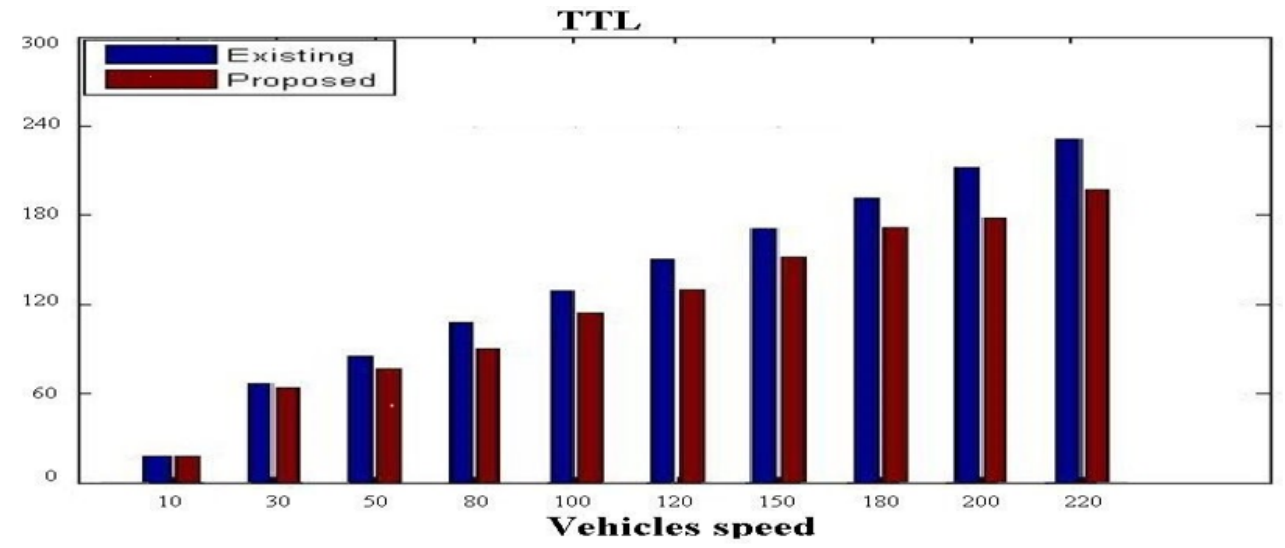

Figure 8. TTL (seconds).

Figure 9 shows the fuzzy sets model gradual properties to model a theoretical possibilities matter the degree of satisfaction, and the data provided with uncertainty and imprecision allows them to be used in a vast variety of applications (RSS) feature of the member function, which also represents the performance of received signal. The received signal leads to obtain the parameter and then it is measured with range of radio. The RSS member function express the total in percent of radio ranges. The values for the $x$-axis are expressed in the range between 0 to $100 \%$; the calculated percentage tells the closeness between two vehicles in the radio range, usually the total radio range is $100 \mathrm{~m}$. The $0 \%$ defines that the smart device is out of radio range and radio signals are unreachable to the smart device, while $100 \%$ defines that the vehicles are close to each other and radio signal frequency is very strong. The communication and data transmission can be done once the radio signal's receiving rate is greater than of 30\%. Effective and strong communication takes place when the rate receiving radio signal is above $70 \%$; this describes that the vehicles are very close to each other; however, there would be no packet or frame loss while communication takes place at a distance.

Figure 10 defines the value of traffic between devices and this value can be high, low and normal. Here the ratio parameter of channel capacity and capture packets is defined. The value of traffic is normal if traffic is represented greater than $30 \%$ but less than $70 \%$ in the channel capacity. Moreover, the value of traffic can be seen low if capacity of radio signal is less than of $30 \%$, finally the value of traffic can be high if capacity of radio signal is less than of $70 \%$. 


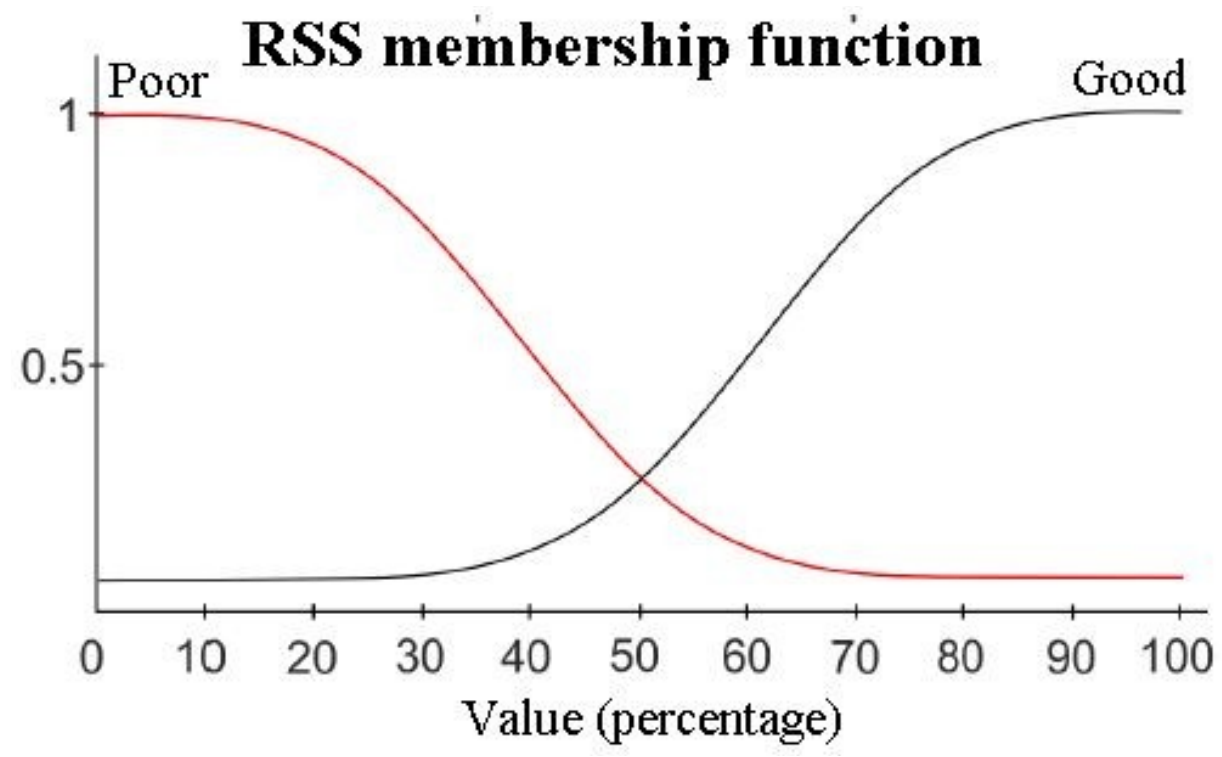

Figure 9. Really Simple Syndication (RSS) membership function.

\section{Traffic membership function}

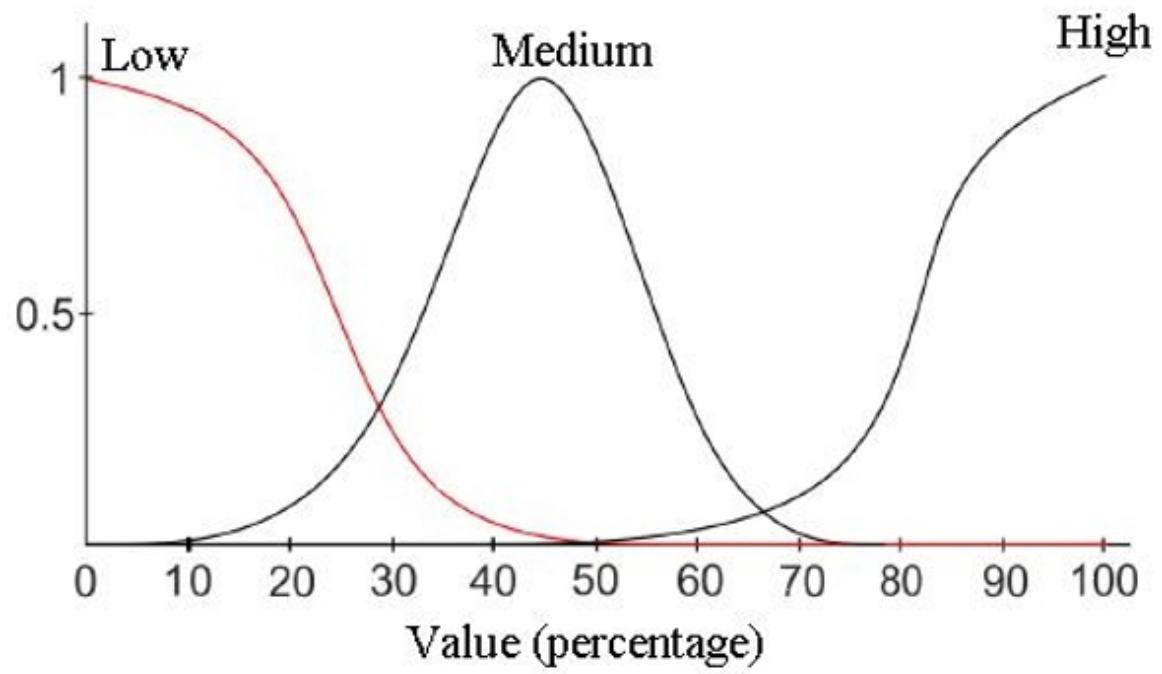

Figure 10. Fuzzy logic for traffic membership function in percentage (\%).

Figure 11 defines the signal interference ration (SIR) parameter for the calculated range of every cluster, and this wanted a signal energy to interfere with the vehicles range. However, the interference is dedicated for each device on selected cluster, and this is satisfied once the value is greater than 1 ; however, cluster is unsatisfied for the vehicle if the value is less than 1 . Once the member function has been defined for every parameter, the next step of definition is to define the heuristic rules. 


\section{SIR membership function}

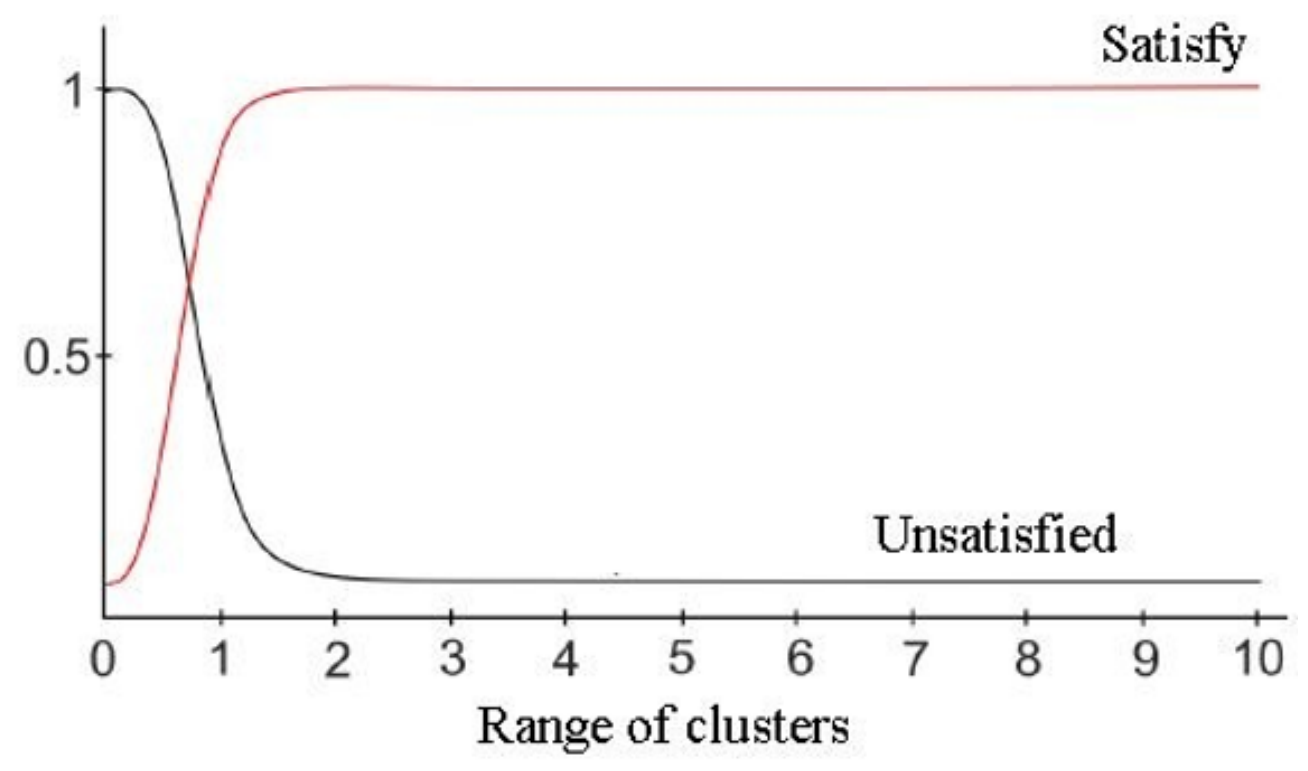

Figure 11. Signal interference ration (SIR) membership function in fuzzy logic.

The channel assignment mechanism needs to select the cluster first and then take the value for the vehicle figure's rank. Figure 12 shows the output of the fuzzy logic of Node 1. The value of every vehicle's rank depends on the input parameters and set of heuristic rules described in FL fuzzy logic. The maximum value illustrates the effectiveness of channel of communication. Here the fuzzy logic runs on very device and in-fact the parameters can vary depending on the quantity of vehicles within the radio range. PU activity, traffic, and channel ranking support cluster selection.

\section{Fuzzy logic output ranking of vehicles}

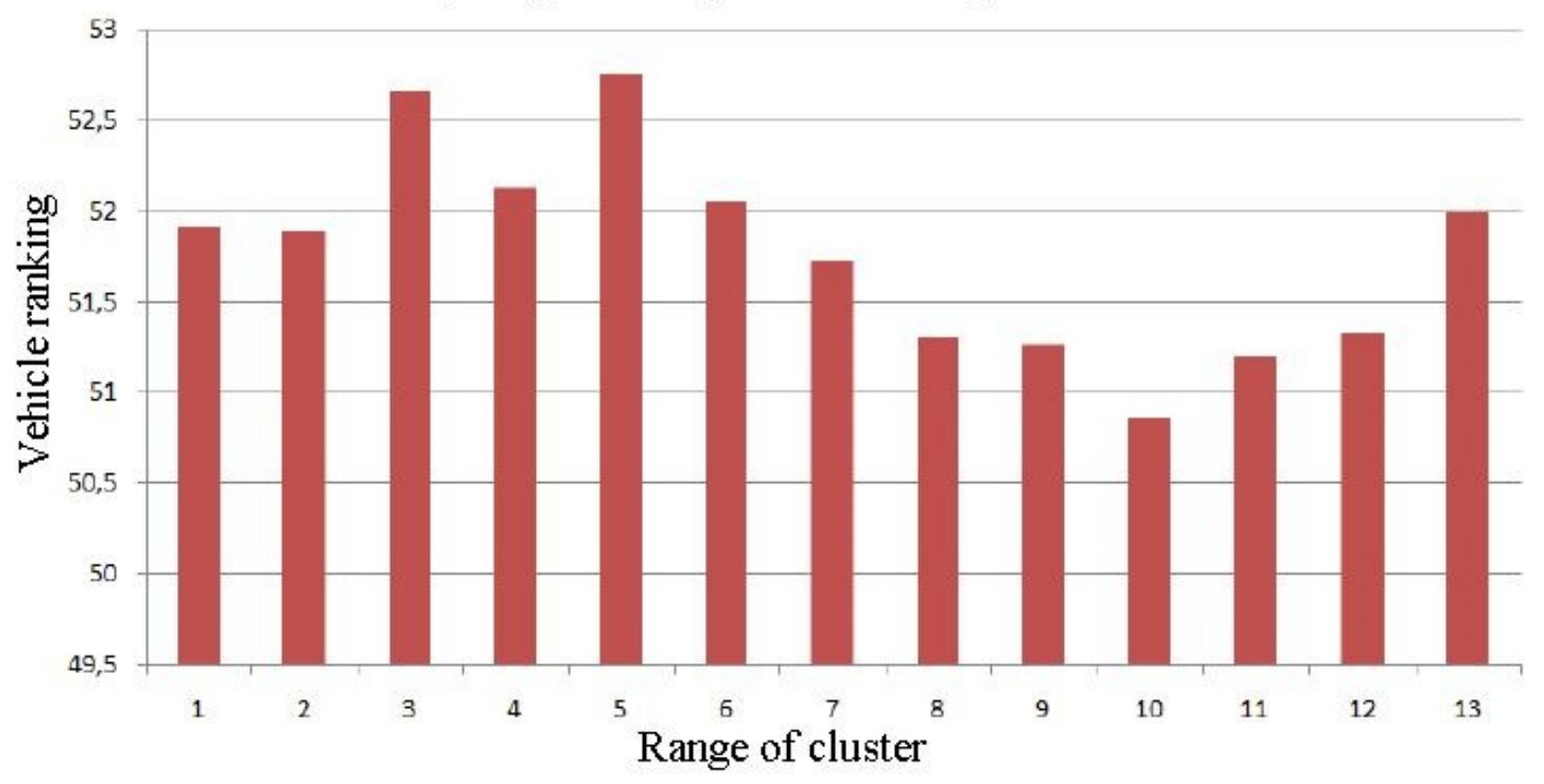

Figure 12. Fuzzy logic output ranking of vehicle.

The higher vehicle rank value is shown that defines the more effectiveness of vehicle rank for communication. Only one parameter, based on rank, is not enough to express the communication quality. Because of the high SIR (signal interference ration) value of 
communication channel can encompass more traffic. However, the channel having more traffic for the communication is not reliable, since channels have no space for the packets.

\section{Conclusions}

The VANET is variable-infrastructure, decentralized, and self-organizing connectivity of WSDs wireless vehicles, allowing communication between different WSDs inside the transmission range. In this research, we performed the mobility modeling evaluation through EEFM with IoT in VANET, using the location of vehicle gadgets. We analyzed the supposed FL fuzzy logic rules and checked the probability of connection, determined through EEFM with IoT in VANET. The proposed method implemented and tested the evaluated results having high-throughput, efficient and smooth values. Here, we concluded that the EEFM with IoT in VANET system could generate accurate communication data with IoT in VANET. Our prosed method is different from the existing method [84] because three parameters, namely the (1) distance of each node, (2) remaining energy, and (3) number of neighbors of every node, were considered as fuzzy criteria. Results of this research compared to various other algorithms in relation to parameters like dead node in every round, the first node expires, half node expire, last node expire, and the network lifetime. The simulation results show that the proposed approach outperforms other methods. On the other hand, the VANET environment is vulnerable at the time of data transmission, compared to the existing protocols, such as fuzzy-IoT, two fuzzy, and FDMS. The performance comparison also emphasizes the effective utilization of the resources. Simulations on highway environment show that the suggested protocol has an improved QoS efficiency compared to the above published methods in the literature. We proposed the method discussed overhead, aggregation time, time to live, RRS membership function, and traffic membership function shown in the Results section. We will propose mobile vehicle privacy, using the clustering method to secure communication in fog computing in future work.

Author Contributions: Conceptualization, I.M. and R.A.S.; Data curation, R.A.S.; Formal analysis, M.K.H. and M.H.T.; Funding acquisition, M.K.H.; Investigation, I.M. and M.K.H.; Methodology, I.M. and R.A.S.; Project administration, M.K.H.; Resources, M.H.T.; Software, M.K.H.; Validation, I.M.; Writing-original draft, R.A.S.; Writing-review \& editing, M.K.H., J.N., K.A.A.B., E.H. and M.H.T. All authors have read and agreed to the published version of the manuscript.

Funding: This research was supported by the research grant of Universiti Kebangsaan Malaysia (UKM), under the grants FRGS/1/2020/ICT03/UKM/02/6 and TAP-K021445 respectively.

Data Availability Statement: All data are available with this manuscript.

Conflicts of Interest: The authors declare that there are no conflicts of interest regarding the publish.

\section{References}

1. Qafzezi, E.; Bylykbashi, K.; Ikeda, M.; Matsuo, K.; Barolli, L. Coordination and management of cloud, fog and edge resources in SDN-VANETs using fuzzy logic: A comparison study for two fuzzy-based systems. Internet Things 2020, 11, 100169. [CrossRef]

2. Bylykbashi, K.; Qafzezi, E.; Ikeda, M.; Matsuo, K.; Barolli, L. Fuzzy-based driver monitoring system (FDMS): Implementation of two intelligent FDMSs and a testbed for safe driving in VANETs. Future Gener. Comput. Syst. 2020, 105, 665-674. [CrossRef]

3. Cui, J.; Wei, L.; Zhong, H.; Zhang, J.; Xu, Y.; Liu, L. Edge computing in VANETs-An efficient and privacy-preserving cooperative downloading scheme. IEEE J. Sel. Areas Commun. 2020, 38, 1191-1204. [CrossRef]

4. Awan, K.A.; Din, I.U.; Almogren, A.; Guizani, M.; Khan, S. StabTrust-A stable and centralized trust-based clustering mechanism for IoT enabled vehicular ad-hoc networks. IEEE Access 2020, 8, 21159-21177. [CrossRef]

5. Memon, I.; Mirza, H.T. MADPTM: Mix zones and dynamic pseudonym trust management system for location privacy. Int. J. Commun. Syst. 2018, 31, e3795. [CrossRef]

6. Memon, I.; Mirza, H.T.; Arain, Q.A.; Memon, H. Multiple mix zones de-correlation trajectory privacy model for road network. Telecommun. Syst. 2019, 70, 557-582. [CrossRef]

7. Alshehri, M.D.; Hussain, F.K. A fuzzy security protocol for trust management in the internet of things (Fuzzy-IoT). Computing 2019, 101, 791-818. [CrossRef]

8. Ozera, K.; Bylykbashi, K.; Liu, Y.; Barolli, L. A fuzzy-based approach for cluster management in VANETs: Performance evaluation for two fuzzy-based systems. Internet Things 2018, 3, 120-133. [CrossRef] 
9. Hasan, M.K.; Ismail, A.F.; Abdalla, A.H.; Abdullah, K.; Ramli, H.; Islam, S.; Saeed, R.A. Inter-cell interference coordination in LTE-A HetNets: A survey on self organizing approaches. In Proceedings of the 2013 International Conference on Computing, Electrical and Electronic Engineering (ICCEEE), Khartoum, Sudan, 26-28 August 2013; pp. 196-201.

10. Xu, W.; Zhou, H.; Cheng, N.; Lyu, F.; Shi, W.; Chen, J.; Shen, X. Internet of vehicles in big data era. IEEE/CAA J. Autom. Sin. 2018, 5, 19-35. [CrossRef]

11. Ammar, M.; Russello, G.; Crispo, B. Internet of things: A survey on the security of IoT frameworks. J. Inf. Secur. Appl. 2018, 38, 8-27. [CrossRef]

12. Hasan, M.K.; Ismail, A.F.; Islam, S.; Hashim, W.; Ahmed, M.M.; Memon, I. A novel HGBBDSA-CTI approach for subcarrier allocation in heterogeneous network. Telecommun. Syst. 2019, 70, 245-262. [CrossRef]

13. Kotis, K.; Athanasakis, I.; Vouros, G.A. Semantically enabling IoT trust to ensure and secure deployment of IoT entities. Int. J. Internet Things Cyber-Assur. 2018, 1, 3. [CrossRef]

14. Mosenia, A.; Jha, N.K. A comprehensive study of security of internet-of-things. IEEE Trans. Emerg. Top. Comput. 2016, 5, 586-602. [CrossRef]

15. Tuna, G.; Kogias, D.G.; Gungor, V.C.; Gezer, C.; Taşkın, E.; Ayday, E. A survey on information security threats and solutions for Machine to Machine (M2M) communications. J. Parallel Distrib. Comput. 2017, 109, 142-154. [CrossRef]

16. Yang, Q.; Jang, S.-J.; Yoo, S.-J. Q-learning-based fuzzy logic for multi-objective routing algorithm in flying Ad Hoc networks. Wirel. Pers. Commun. 2020, 113, 115-138. [CrossRef]

17. Hasan, M.K.; Yousoff, S.H.; Ahmed, M.M.; Hashim, A.H.A.; Ismail, A.F.; Islam, S. Phase offset analysis of asymmetric communications infrastructure in smart grid. Elektron. Elektrotechnika 2019, 25, 67-71. [CrossRef]

18. Memon, I.; Ali, Q.; Zubedi, A.; Mangi, F.A. DPMM: Dynamic pseudonym-based multiple mix-zones generation for mobile traveler. Multimed. Tools Appl. 2017, 76, 24359-24388. [CrossRef]

19. Spaho, E.; Sakamoto, S.; Barolli, L.; Xhafa, F.; Ikeda, M. Trustworthiness in P2P: Performance behaviour of two fuzzy-based systems for JXTA-overlay platform. Soft Comput. 2014, 18, 1783-1793. [CrossRef]

20. Akhtar, R.; Shengua, Y.; Zhiyu, Z.; Khan, Z.A.; Memon, I.; Rehman, S.; Awan, S. Content distribution and protocol design issue for mobile social networks: A survey. EURASIP J. Wirel. Commun. Netw. 2019, 2019, 128. [CrossRef]

21. Vijayan, R.M.; Ezhilarasie, R.; Umamakeswari, A. Implementation of Public-Key Infrastructure for Smart Parking System Using MQTT Protocol. In Inventive Communication and Computational Technologies; Metzler, J.B., Ed.; Springer: Singapore, 2020; pp. 1029-1037.

22. Memon, I.; Memon, H.; Arain, Q.A. Pseudonym Changing Strategy with Mix Zones Based Authentication Protocol for Location Privacy in Road Networks. Wirel. Pers. Commun. 2021, 116, 3309-3329. [CrossRef]

23. Manikandan, S.; Jeyakarthic, M. An Energy-Efficient Distributed Unequal Clustering Approach for Lifetime Maximization in Wireless Sensor Network. In EAI International Conference on Big Data Innovation for Sustainable Cognitive Computing; Springer: Cham, Switzerland, 2020; pp. 63-76.

24. Sert, S.A.; Bagci, H.; Yazici, A. MOFCA: Multi-objective fuzzy clustering algorithm for wireless sensor networks. Appl. Soft Comput. 2015, 30, 151-165. [CrossRef]

25. Bagci, H.; Yazici, A. An energy aware fuzzy approach to unequal clustering in wireless sensor networks. Appl. Soft Comput. 2013, 13, 1741-1749. [CrossRef]

26. Memon, I. Distance and clustering-based energy-efficient pseudonyms changing strategy over road network. Int. J. Commun. Syst. 2018, 31, e3704. [CrossRef]

27. Khalifeh, A.; Rajendiran, K.; Darabkh, K.A.; Khasawneh, A.M.; Almomani, O.; Zinonos, Z. On the potential of fuzzy logic for solving the challenges of cooperative multi-robotic wireless sensor networks. Electronics 2019, 8, 1513. [CrossRef]

28. Balakrishnan, B.; Balachandran, S. FLECH: Fuzzy logic based energy efficient clustering hierarchy for nonuniform wireless sensor networks. Wirel. Commun. Mob. Comput. 2017, 2017, 1-13. [CrossRef]

29. Bylykbashi, K.; Elmazi, D.; Matsuo, K.; Ikeda, M.; Barolli, L. Effect of security and trustworthiness for a fuzzy cluster management system in VANETs. Cogn. Syst. Res. 2019, 55, 153-163. [CrossRef]

30. Mazinani, A.; Mazinani, S.M.; Mirzaie, M. FMCR-CT: An energy-efficient fuzzy multi cluster-based routing with a constant threshold in wireless sensor network. Alex. Eng. J. 2019, 58, 127-141. [CrossRef]

31. Mostafa, M.; Mazinani, S.M. MACHFL-FT: A fuzzy logic based energy-efficient protocol to cluster heterogeneous nodes in wireless sensor networks. Wirel. Netw. 2019, 25, 4597-4609.

32. Thangaramya, K.; Kulothungan, K.; Gandhi, S.I.; Selvi, M.; Kumar, S.V.N.; Arputharaj, K. Intelligent fuzzy rule-based approach with outlier detection for secured routing in WSN. Soft Comput. 2020, 24, 16483-16497. [CrossRef]

33. Qureshi, K.N.; Islam, F.U.; Kaiwartya, O.; Kumar, A.; Lloret, J. Improved road segment-based geographical routing protocol for vehicular Ad-Hoc networks. Electronics 2020, 9, 1248. [CrossRef]

34. Singh, J.; Singh, K. Advanced VANET information dissemination scheme using Fuzzy logic. In Proceedings of the 2018 IEEE 8th Annual Computing and Communication Workshop and Conference (CCWC), Piscataway, NJ, USA, 8-10 January 2018; pp. 874-879.

35. Singh, S.; Singh, S.; Banga, V.K. Design of fuzzy logic system framework using evolutionary techniques. Soft Comput. 2020, 24, 4455-4468. [CrossRef] 
36. Hou, S.; Chen, C.; Chu, Y.; Fei, J. Experimental validation of modified adaptive fuzzy control for power quality improvement. IEEE Access 2020, 8, 1. [CrossRef]

37. Tran, T.N.; Nguyen, T.-V.; An, B. An efficient connected dominating set clustering based routing protocol with dynamic channel selection in cognitive mobile Ad Hoc networks. Electronics 2019, 8, 1332. [CrossRef]

38. Zhou, T.; Liu, C.; Liu, X.; Wang, H.; Zhou, Y. Finite-time prescribed performance adaptive fuzzy control for unknown nonlinear systems. Fuzzy Sets Syst. 2020, 402, 16-34. [CrossRef]

39. Memon, I.; Fazal, H.; Shaikh, R.A.; Mallah, G.A.; Arain, R.H.; Muhammad, G. Smart Intelligent System for Mobile Travelers Based on Fuzzy Logic in IoT Communication Technology. In International Conference on Intelligent Technologies and Applications; Springer: Singapore, 2019; pp. 22-31.

40. Precup, R.E.; Teban, T.A.; Albu, A.; Borlea, A.B.; Zamfirache, I.A.; Petriu, E.M. Evolving fuzzy models for prosthetic hand myoelectric-based control. IEEE Trans. Instrum. Meas. 2020, 69, 4625-4636. [CrossRef]

41. Dombi, J.; Hussain, A. A new approach to fuzzy control using the distending function. J. Process. Control 2020, 86, 16-29. [CrossRef]

42. Kouzbary, M.A.; Osman, N.A.; Kouzbary, H.A.; Shasmin, H.N.; Arifin, N. Towards universal control system for powered ankle-foot prosthesis: A simulation study. Int. J. Fuzzy Syst. 2020, 24, 1299-1313. [CrossRef]

43. Singh, S.P.; Panda, A.; Panda, A.K. A novel interval type-2 fuzzy based direct torque control of induction motor drive using five-level diode-clamped inverter. IEEE Trans. Ind. Electr. 2020, 1, 149-159.

44. Taran, B.; Pirmohammadi, A. Designing an optimal fuzzy sliding mode control for a two-link robot. J. Braz. Soc. Mech. Sci. Eng. 2019, 42, 5. [CrossRef]

45. Shukla, A.K.; Muhuri, P.K.; Abraham, A. A bibliometric analysis and cutting-edge overview on fuzzy techniques in Big Data. Eng. Appl. Artif. Intell. 2020, 92, 103625. [CrossRef]

46. Hasan, M.K.; Ismail, A.F.; Abdalla, A.H.; Ramli, H.A.M.; Islam, S.; Hashim, W.; Badron, K. Cluster-based spectrum sensing scheme in heterogeneous network. In Theory and Applications of Applied Electromagnetics; Springer: Cham, Switzerland, 2015; pp. 1-11.

47. Mohammadani, K.H.; Memon, K.A.; Memon, I.; Hussaini, N.N.; Fazal, H. Preamble time-division multiple access fixed slot assignment protocol for secure mobile ad hoc networks. Int. J. Distrib. Sens. Netw. 2020, 16, 1550147720921624. [CrossRef]

48. Xue, K.; Yang, Q.; Li, S.; Wei, D.S.L.; Peng, M.; Memon, I.; Hong, P. PPSO: A privacy-preserving service outsourcing scheme for real-time pricing demand response in smart grid. IEEE Internet Things J. 2018, 6, 2486-2496. [CrossRef]

49. Haider, S.; Abbas, G.; Abbas, Z.H.; Boudjit, S.; Halim, Z. PDACCA: A probabilistic direction-aware cooperative collision avoidance scheme for VANETs. Future Gener. Comput. Syst. 2020, 103, 1-17. [CrossRef]

50. Du, J.; Wang, S.; Zhang, B. Vehicle density and signal to noise ratio based broadcast backoff algorithm for VANETs. Ad Hoc Netw. 2020, 99, 102071. [CrossRef]

51. Chen, Q.; Schmidt-Eisenlohr, F.; Jiang, D.; Torrent-Moreno, M.; Delgrossi, L.; Hartenstein, H. Overhaul of IEEE 802.11 modeling and simulation in ns-2. In Proceedings of the 10th ACM Symposium on Modeling, Analysis, and Simulation of Wireless and Mobile Systems, New York, NY, USA, 1 January 2020; pp. 159-168.

52. Hatzivasilis, G.; Soultatos, O.; Ioannidis, S.; Spanoudakis, G.; Katos, V.; Demetriou, G. MobileTrust: Secure knowledge integration in VANETs. ACM Trans. Cyber-Phys. Syst. 2020, 4, 1-25. [CrossRef]

53. Feng, W.; Alshaer, H.; Elmirghani, J. Green information and communication technology: Energy efficiency in a motorway model. IET Commun. 2010, 4, 850. [CrossRef]

54. Elhoseny, M.; Shankar, K. Energy Efficient Optimal Routing for Communication in VANETs via Clustering Model. In Emerging Technologies for Connected Internet of Vehicles and Intelligent Transportation System Networks; Metzler, J.B., Ed.; Springer: Cham, Switzerland, 2019; pp. 1-14.

55. Lu, X.; Xiao, L.; Xu, T.; Zhao, Y.; Tang, Y.; Zhuang, W. Reinforcement learning based PHY authentication for VANETs. IEEE Trans. Veh. Technol. 2020, 69, 3068-3079. [CrossRef]

56. Song, H.; Wen, H.; Tang, J.; Chen, Y.; Xie, F.; Liao, R.-F.; Chen, S. PLS-based secrecy transmission for VANETs. IEEE Trans. Veh. Technol. 2020, 69, 7596-7608. [CrossRef]

57. Deng, Z.; Cai, Z.; Liang, M. A multi-hop VANETs-assisted offloading strategy in vehicular mobile edge computing. IEEE Access 2020, 8, 53062-53071. [CrossRef]

58. Mirjalili, S. Moth-flame optimization algorithm: A novel nature-inspired heuristic paradigm. Knowledge-Based Syst. 2015, 89, 228-249. [CrossRef]

59. Abro, A.; Zhongliang, D.; Memon, K.A.; Mohammadani, K.H.; Ain, N.U.; Memon, S.; Memon, I.; Panhwar, M.A. Minimizing Energy Expenditures using Genetic Algorithm for Scalability and Longlivety of Multi hop Sensor Networks. In Proceedings of the 2019 IEEE 9th International Conference on Electronics Information and Emergency Communication (ICEIEC), Beijing, China, 12-14 July 2019; pp. 183-187.

60. Li, J.; Wang, Y.; McAuley, J. Time Interval Aware Self-Attention for Sequential Recommendation. In Proceedings of the 13th International Conference on Web Search and Data Mining, Houston, TX, USA, 3-7 February 2020; pp. 322-330.

61. Zhang, Y.; Kong, L.; Wang, F.; Li, B.; Ma, C.; Chen, D.; Liu, K.; Fan, C.; Zhang, H. Information stored in nanoscale: Encoding data in a single DNA strand with Base64. Nano Today 2020, 33, 100871. [CrossRef] 
62. Usama, M.; Rehman, O.; Memon, I.; Rizvi, S. An efficient construction of key-dependent substitution box based on chaotic sine map. Int. J. Distrib. Sens. Netw. 2019, 15, 1550147719895957. [CrossRef]

63. Memon, I.; Chen, L.; Arain, Q.A.; Memon, H.; Chen, G. Pseudonym changing strategy with multiple mix zones for trajectory privacy protection in road networks. Int. J. Commun. Syst. 2018, 31, e3437. [CrossRef]

64. Arain, Q.A.; Memon, H.; Memon, I.; Memon, M.H.; Shaikh, R.A.; Mangi, F.A. Intelligent travel information platform based on location base services to predict user travel behavior from user-generated GPS traces. Int. J. Comput. Appl. 2017, 39, 155-168. [CrossRef]

65. Gustav, Y.H.; Wang, Y.; Domenic, M.K.; Zhang, F.; Memon, I. Velocity similarity anonymization for continuous query Location based services. In Proceedings of the 2013 International Conference on Computational Problem-Solving (ICCP), Jiuzhai Valley, China, 26-28 October 2013; pp. 433-436.

66. Arain, Q.A.; Memon, I.; Deng, Z.; Memon, M.H.; Mangi, F.A.; Zubedi, A. Location monitoring approach: Multiple mix-zones with location privacy protection based on traffic flow over road networks. Multimedia Tools Appl. 2017, 77, 5563-5607. [CrossRef]

67. Domenic, M.K.; Wang, Y.; Zhang, F.; Memon, I.; Gustav, Y.H. Preserving users' privacy for continuous query services in road networks. In Proceedings of the 2013 6th International Conference on Information Management, Innovation Management and Industrial Engineering, Xi'an, China, 23-24 November 2013; Volume 1, pp. 352-355.

68. Arain, Q.A.; Deng, Z.; Memon, I.; Zubedi, A.; Jiao, J.; Ashraf, A.; Khan, M.S. Privacy protection with dynamic pseudonym-based multiple mix-zones over road networks. China Commun. 2017, 14, 89-100. [CrossRef]

69. Arain, Q.A.; Deng, Z.; Memon, I.; Zubedi, A.; Mangi, F.A. Map services based on multiple mix-zones with location privacy protection over road network. Wirel. Pers. Commun. 2017, 97, 2617-2632. [CrossRef]

70. Memon, I.; Arain, Q.A. Dynamic distributed mobility management system based on multiple mix-zones over road networks. arXiv 2017, arXiv:1706.02252.

71. Islam, S.; Hashim, A.-H.A.; Habaebi, M.H.; Hasan, M.K. Design and implementation of a multihoming-based scheme to support mobility management in NEMO. Wirel. Pers. Commun. 2017, 95, 457-473. [CrossRef]

72. Srivastava, A.; Prakash, A.; Tripathi, R. Location based routing protocols in VANET: Issues and existing solutions. Veh. Commun. 2020, 23, 100231. [CrossRef]

73. Gao, H.; Liu, C.; Li, Y.; Yang, X. V2VR: Reliable hybrid-network-oriented V2V data transmission and routing considering RSUs and connectivity probability. IEEE Trans. Intell. Transp. Syst. 2020, 1-14. [CrossRef]

74. Wang, J.; Zhang, H.; Tang, X.; Li, Z. Delay-tolerant routing and message scheduling for CR-VANETs. Futur. Gener. Comput. Syst. 2020, 110, 291-309. [CrossRef]

75. Nafi, N.S.; Hasan, M.K.; Abdallah, A.H. Traffic flow model for vehicular network. In Proceedings of the 2012 International Conference on Computer and Communication Engineering (ICCCE), Kuala Lump, Malaysia, 7 March 2012; pp. 738-743.

76. Hasan, M.K.; Ahmed, M.M.; Musa, S.S.; Islam, S.; Abdullah, S.N.H.S.; Hossain, E.; Nafi, N.S.; Vo, N. An improved dynamic thermal current rating model for PMU-based wide area measurement framework for reliability analysis utilizing sensor cloud system. IEEE Access 2021, 9, 14446-14458. [CrossRef]

77. Muniyandi, R.C.; Hasan, M.K.; Hammoodi, M.R.; Maroosi, A. An improved harmony search algorithm for proactive routing protocol in VANET. J. Adv. Transp. 2021, 2021, 1-17. [CrossRef]

78. Nurelmadina, N.; Hasan, M.K.; Memon, I.; Saeed, R.A.; Ariffin, K.A.; Ali, E.S.; Mokhtar, R.A.; Islam, S.; Hossain, E.; Hassan, M. A systematic review on cognitive radio in low power wide area network for industrial IoT applications. Sustainability 2021, 13, 338. [CrossRef]

79. Akhtaruzzaman, M.; Hasan, M.K.; Kabir, S.R.; Abdullah, S.N.H.S.; Sadeq, M.J.; Hossain, E. HSIC bottleneck based distributed deep learning model for load forecasting in smart grid with a comprehensive survey. IEEE Access 2020, 8, 222977-223008. [CrossRef]

80. Memon, I.; Shaikh, R.A.; Hasan, M.K.; Hassan, R.; Haq, A.U.; Zainol, K.A. Protect mobile travelers information in sensitive region based on fuzzy logic in IoT technology. Secur. Commun. Netw. 2020, 2020, 1-12. [CrossRef]

81. Ahmed, Z.E.; Hasan, M.K.; Saeed, R.A.; Hassan, R.; Islam, S.; Mokhtar, R.A.; Khan, S.; Akhtaruzzaman, M. Optimizing energy consumption for cloud internet of things. Front. Phys. 2020, 8, 358. [CrossRef]

82. Islam, S.; Khalifa, O.O.; Hashim, A.H.A.; Hasan, M.K.; Razzaque, M.A.; Pandey, B. Design and evaluation of a multihoming-based mobility management scheme to support inter technology handoff in PNEMO. Wirel. Pers. Commun. 2020, 114, 1133-1153. [CrossRef]

83. Eltahir, A.A.; Saeed, R.A.; Mukherjee, A.; Hasan, M.K. Evaluation and analysis of an enhanced hybrid wireless mesh protocol for vehicular ad hoc network. EURASIP J. Wirel. Commun. Netw. 2016, 2016, 169. [CrossRef]

84. Kashani, A.; Ghanbari, M.; Rahmani, A.M. Improving performance of opportunistic routing protocol using fuzzy logic for vehicular ad-hoc networks in highways. J. AI Data Minining 2020. [CrossRef] 